\title{
Article \\ Soft X-ray Microscopy Techniques for Medical and Biological Imaging at TwinMic-Elettra
}

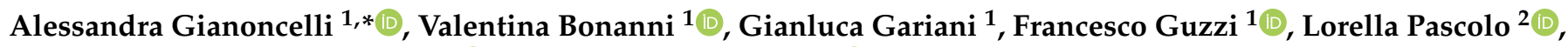 \\ Roberto Borghes ${ }^{1}$, Fulvio Billè ${ }^{1}\left[\right.$ and George Kourousias ${ }^{1}[0$ \\ 1 Elettra-Sincrotrone Trieste, Strada Statale 14—km 163,5 in AREA Science Park, Basovizza, \\ 34149 Trieste, Italy; valentina.bonanni@elettra.eu (V.B.); gianluca.gariani@elettra.eu (G.G.); \\ francesco.guzzi@elettra.eu (F.G.); roberto.borghes@elettra.eu (R.B.); fulvio.bille@elettra.eu (F.B.); \\ george.kourousias@elettra.eu (G.K.) \\ 2 Institute for Maternal and Child Health, IRCCS Burlo Garofolo, Via dell'Istria 65/1, 34137 Trieste, Italy; \\ lorella.pascolo@burlo.trieste.it \\ * Correspondence: alessandra.gianoncelli@elettra.eu
}

Citation: Gianoncelli, A.; Bonanni, V.; Gariani, G.; Guzzi, F.; Pascolo, L.; Borghes, R.; Billè, F.; Kourousias, G. Soft X-ray Microscopy Techniques for Medical and Biological Imaging at TwinMic-Elettra. Appl. Sci. 2021, 11, 7216. https://doi.org/10.3390/ app11167216

Academic Editor: Brian Abbey

Received: 14 July 2021

Accepted: 2 August 2021

Published: 5 August 2021

Publisher's Note: MDPI stays neutral with regard to jurisdictional claims in published maps and institutional affiliations.

Copyright: (c) 2021 by the authors. Licensee MDPI, Basel, Switzerland. This article is an open access article distributed under the terms and conditions of the Creative Commons Attribution (CC BY) license (https:// creativecommons.org/licenses/by/ $4.0 /)$.

\begin{abstract}
Progress in nanotechnology calls for material probing techniques of high sensitivity and resolution. Such techniques are also used for high-impact studies of nanoscale materials in medicine and biology. Soft X-ray microscopy has been successfully used for investigating complex biological processes occurring at micrometric and sub-micrometric length scales and is one of the most powerful tools in medicine and the life sciences. Here, we present the capabilities of the TwinMic soft X-ray microscopy end-station at the Elettra synchrotron in the context of medical and biological imaging, while we also describe novel uses and developments.
\end{abstract}

Keywords: X-ray microscopy; soft X-ray; X-ray fluorescence; ptychography; compressive sensing

\section{Introduction}

X-ray microscopy gathers a cohort of techniques that allows the acquisition of two and/or three-dimensional views of an object at micrometric and sub-micrometric spatial resolutions by the use of $X$-ray radiation $[1,2]$. Soft $X$-ray microscopy, which is a subset of it, employing soft X-ray photons (usually in the 200-2000 eV energy range) as the illumination source, is nowadays a standard technique in synchrotron radiation facilities [3-13]. Even though X-ray microscopy cannot compete with the nanometer or sub-nanometer spatial resolution of electron microscopes, it allows for a more relaxed sample preparation, especially for biological and organic specimens, and for higher penetration depths, thus permitting thicker samples to be analyzed. Moreover, the high sensitivity of X-rayspectro-microscopy, such as X-ray fluorescence (XRF) microscopy, makes it an essential tool for tracking chemical changes at the micro- and nanoscale.

The TwinMic beamline end-station at Elettra [7] is a soft X-ray microscope originally designed to provide a collection of imaging techniques in a single instrument [14], specifically with an easy switch between scanning transmission X-ray microscopy (STXM) and full-field modes. Afterward, STXM has become the more dominant operation mode, especially due to the development of the first worldwide low-energy X-ray fluorescence (LEXRF) system [15-17].

TwinMic capabilities have attracted the interest of scientists from different research fields, from the material sciences [18], especially from the energy field [19-22], to environmental sciences [23-31], the life sciences [32-46], and cultural heritage [47].

In the present manuscript, we describe the TwinMic imaging and spectroscopic techniques made available especially to the biological and medical user community. We highlight the TwinMic potentialities and the recent achievements in the medical and biological field through suitable research cases, demonstrating its contribution and complementarity with other microscopy approaches. 
Finally, we introduce new ongoing developments regarding advanced smart data acquisition solutions and novel data analysis methods.

\section{Materials and Methods}

2.1. TwinMic Imaging Modes

The present section illustrates in detail the TwinMic Imaging Modes, which are also summarized in Table 1.

Table 1. Summary of TwinMic techniques.

\begin{tabular}{|c|c|c|c|c|c|}
\hline Technique & $\begin{array}{c}\text { Spatial } \\
\text { Resolution } \\
{[\mu \mathrm{m}]}\end{array}$ & $\begin{array}{c}\text { Typical } \\
\text { Acquisition } \\
\text { Time/Pixel [s] }\end{array}$ & $\begin{array}{c}\text { Overall } \\
\text { Acquisition Time } \\
{[\mathrm{h}]}\end{array}$ & $\begin{array}{l}\text { Field of View } \\
{[\mu \mathrm{m}]}\end{array}$ & Detector Type \\
\hline STXM & $0.08-2$ & $0.005-0.05$ & $0.1-2$ & $\begin{array}{l}\text { 10-80 with piezo } \\
\text { motors; } 1000 \text { with } \\
\text { stepper motors }{ }^{1}\end{array}$ & EMCCD $^{2}$ \\
\hline LEXRF & $0.4-2$ & $1-10$ & $2-10$ & $\begin{array}{l}\text { 10-80 with piezo } \\
\text { motors; } 1000 \text { with } \\
\text { stepper motors }{ }^{1}\end{array}$ & SDD \\
\hline Ptychography ${ }^{3}$ & $<0.04$ & $0.1-10$ & $0.05-0.5$ & $10-80$ & $\mathrm{CCD}$ \\
\hline Full-field ${ }^{3}$ & $0.02-0.05$ & $\begin{array}{l}\text { few seconds or } \\
\text { fractions of } \\
\text { seconds }\end{array}$ & $\begin{array}{l}\text { few seconds or } \\
\text { fractions of } \\
\text { seconds }\end{array}$ & 20 & CCD \\
\hline
\end{tabular}

${ }^{1}$ Recently, with compressive sensing (CS) implementation and sample stage upgrade, we have been able to reach fields of view of about $1 \mathrm{~mm} \times 1 \mathrm{~mm} .{ }^{2}$ Electron-multiplying CCD. ${ }^{3}$ Here, we report the values for full frame acquisition.

\subsubsection{Scanning Transmission X-ray Microscopy}

STXM is nowadays a standard X-ray microscopy technique, used especially in the soft or milder X-ray regime. It requires suitable X-ray optics, usually zone plate (ZP) diffractive optics, to focus the $\mathrm{X}$-ray photons on the sample plane, where the specimen is usually scanned across the microprobe. In a few cases, the beam can be scanned across the sample [4]. In scanning techniques, the spatial resolution is determined by the probe size.

For each point in the raster scan, the transmitted X-rays are collected by means of suitable detectors (photodiode, ionization chamber, CCD ... ), allowing one to record the absorption signal. In the case of a two-dimensional detector, as with the TwinMic beamline, in addition to the absorption image, differential phase contrast and darkfield contrast can be acquired simultaneously, providing a complementary imaging mode [48-51]. According to the incident beam intensity and the detector characteristics, where the transmitted signals are intrinsically acquired in a serial way, STXM images may require from a few minutes to several tens of minutes. However, by means of suitable detectors, the scanning operation mode also allows for the simultaneous acquisition of other signals point-bypoint in the raster scan, such as XRF photons [15] or photoelectrons [52] emitted by the sample. Thus, besides morphological images, chemical ones can be obtained. Similarly, by collecting a stack of absorption images across the absorption edge of specific elements, after suitable image alignment, one can extract $\mathrm{X}$-ray absorption near-edge spectroscopy (XANES) signals, which allows for element speciation identification $[4,8,10]$.

A schematic view of the TwinMic STXM operation mode is presented in Figure 1. A series of pinholes of different dimensions acts as a secondary source for the microscope. The incoming monochromatic beam is focused on the sample plane through ZP diffractive optics, whose first diffraction order is selected by the order sorting aperture. The size of the focused beam is given by the secondary source size demagnified through the ZP. For the experiments shown here, a $600 \mu \mathrm{m}$ diameter $\mathrm{Au} \mathrm{ZP}$ with a $50 \mathrm{~nm}$ outermost zone was used. The transmitted X-rays are collected by an electron multiplying CCD (EMCCD) camera DV860 from Andor Technology $\left(128 \times 128\right.$ pixels, $24 \times 24 \mu \mathrm{m}^{2}$ pixel size $)$ by means of an X-ray-visible light converting system constituted by a P43 phosphor screen, a visible light lens, a mirror tilted by $45^{\circ}$, and an objective lens mounted on the CCD camera itself [50]. 


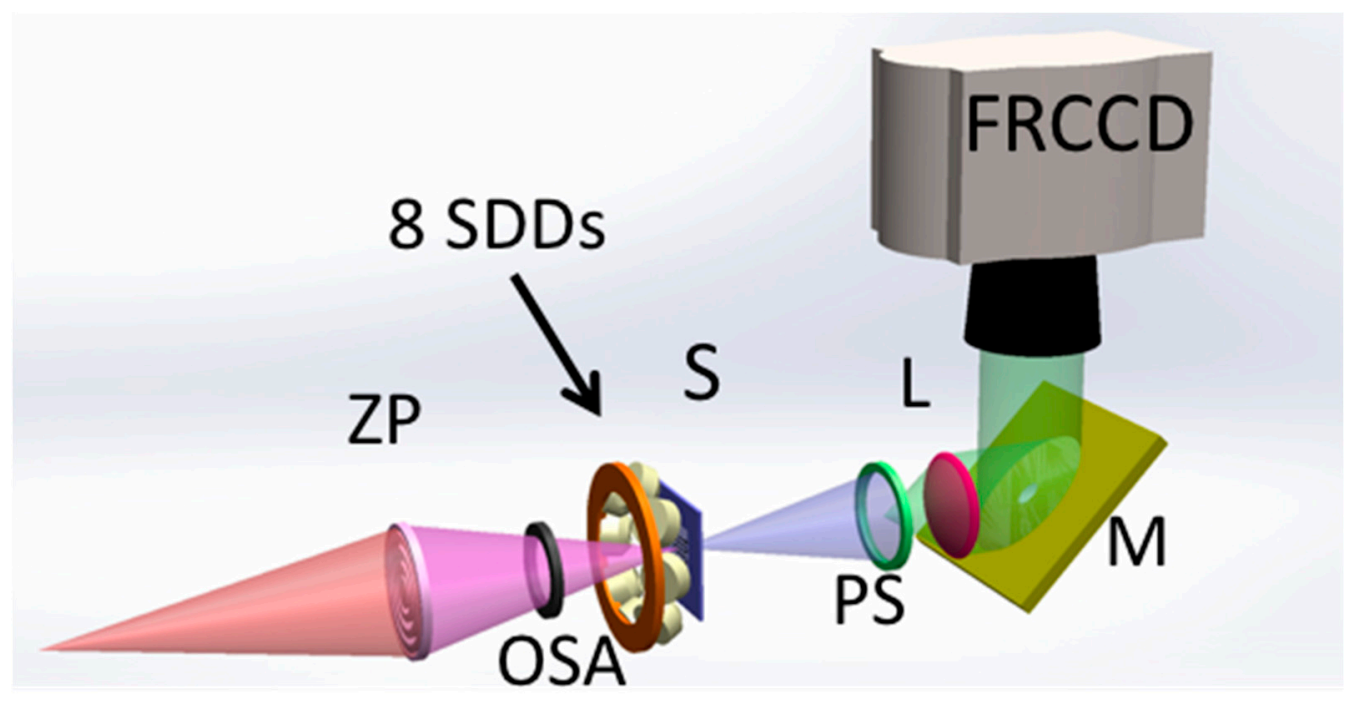

Figure 1. Schematic view of the TwinMic STXM mode setup with the microprobe forming zone plate (ZP) on the specimen (S), diffraction order-selecting aperture (OSA), transmission detection system with fast-read-out CCD camera (FRCCD) and visible light converting system (VLCS), and low-energy X-ray fluorescence (LEXRF) detector system based on 8 silicon drift detectors (SDDs) in backscattered configuration. The VLCS consists of a phosphor screen (PS), a lens (L) and a $45^{\circ}$-tilted mirror (M).

Eight silicon drift detectors (SDDs) are mounted circularly and symmetrically, with their axes placed at $20^{\circ}$ from the sample plane and their center $28 \mathrm{~mm}$ from the focal spot $[15,16]$. The output signal of the preamplifier electronics (XGLab srl, Bruker Nano-Analytics), which is placed in the TwinMic vacuum chamber in close proximity to the SDD chip, is then processed through the DANTE Digital Pulse Processor (XGLab srl, Bruker Bruker NanoAnalytics) [53]. A new SDD system consisting of 4 trapezoid chips, each with 8 square SDDs on it, is under development and has been already tested [54-56], and it is sketched in Figure 2. The new system will cover a larger solid angle (5 to 10 times higher) than the current one, allowing for faster measurements and, thus, reduced radiation damage. Once optimized, it will replace the current LEXRF system.

A

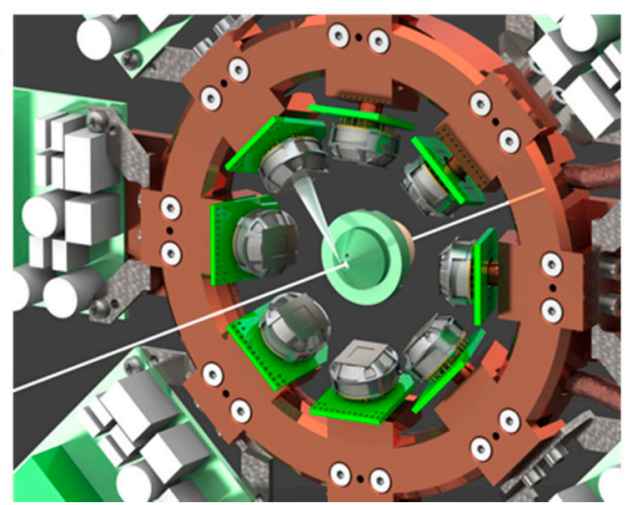

B

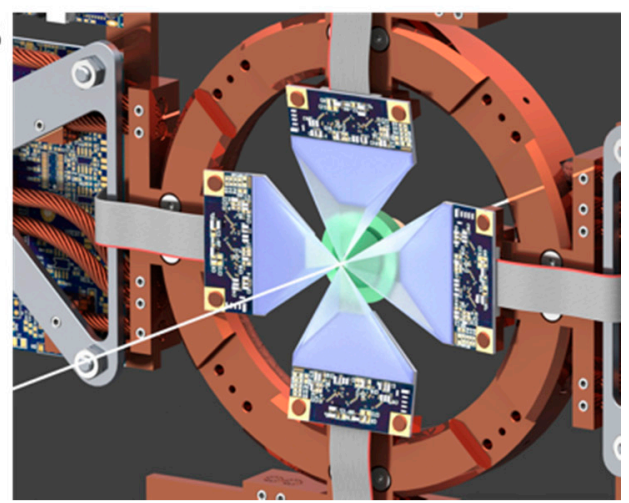

Figure 2. Schematic view of the TwinMic current (A) and future (B) LEXRF system setup.

While LEXRF mapping is a standard TwinMic acquisition mode, XANES spectroscopy is currently under development. It has already been performed on materials sciencerelated topics $[18,22,57]$, where metal concentrations were high enough to detect speciation changes; however, in order to become a standard TwinMic technique, it requires fine tuning and some changes in the beamline acquisition/control software.

The scanning stage where the sample is located consists of two $X$ and $Y$ stepper motors, where a $\mathrm{X}-\mathrm{Y}$ piezoelectric motor stage (with $80 \mu \mathrm{m}$ range of movement) is mounted. In the 
first version of the sample stage, the scanning was performed exclusively by using the piezoelectric motors, after positioning the sample in the desired area by means of the stepper motors, allowing a movement range of $5 \mathrm{~mm}$ in both $X$ and $Y[7,17]$. A newer version of it was recently installed by replacing the mechanics and the stepper motors, allowing for a larger range of movement $(12 \mathrm{~mm} \times 12 \mathrm{~mm})$. This allows for larger samples and/or a larger number of samples to be mounted, avoiding several vacuum breaks and, therefore, reducing the measurements' deadtimes. Moreover, with the new sample stage, both STXM and XRF can be performed not only by using the piezoelectric motors, as originally designed, but also in a coarser way by using the stepper motors themselves. This allows for larger areas to be scanned, as it is shown in the results section.

\subsubsection{Full-Field X-ray Microscopy (TXM)}

TwinMic was originally designed to be able to operate both in STXM and TXM mode with an easy switch between them [14]. Finally, the STXM mode resulted in the most requested one, because of the increasing interest of the scientific community to the newly developed LEXRF. Indeed, scanning instruments are well suited to combine imaging and spectroscopy measurements for a given fixed X-ray energy. On the other hand, the TXM mode offers a faster acquisition time, of the order of seconds, and a higher spatial resolution. For this reason, it is usually well suited for monitoring dynamic changes in the sample or for the tomography experiment, where multiple images are taken sequentially.

The TwinMic TXM mode is summarised in Figure 3. A condenser ZP (CPZ) optics illuminates an area of the sample, which is magnified through a high-resolution ZP on an imaging detector. The CZP used at TwinMic is $1 \mathrm{~mm}$ in diameter and consists of 256 grating elements in 5 rings. The grating constant is $218 \mathrm{~nm}$ for the innermost ring and $126 \mathrm{~nm}$ for the outermost ring. Each grating covers an area of $50 \times 50 \mu \mathrm{m}^{2}$. CZPs were fabricated by Zoneplates.com. The transmitted X-rays are collected by a back-illuminated Princeton CCD camera with $1340 \times 1300$ pixels, a pixel size of $20 \times 20 \mu \mathrm{m}^{2}$, and a $2 \mathrm{~s}$ readout time when a full frame is acquired $[7,17]$.

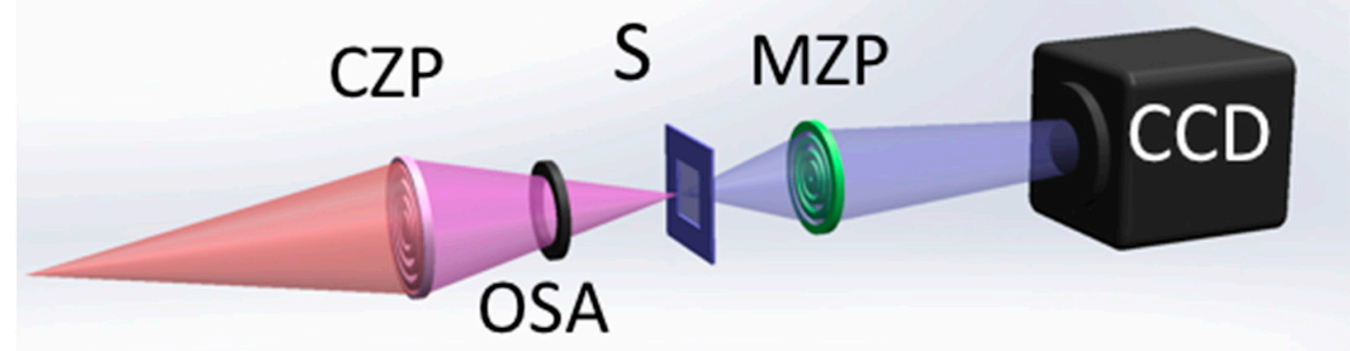

Figure 3. Schematic view of the TwinMic full field imaging mode setup, with a condenser ZP (CZP) illuminating the specimen (S), an order-selecting aperture (OSA), and a micro zone plate (MZP) that magnifies the image of the specimen into the detector with a directly illuminated CCD camera.

\subsubsection{Ptychography and Coherent Diffraction Imaging (CDI)}

Ptychography $[58,59]$ is an emerging scanning imaging technique based on CDI [60-63]. It is attracting interest at synchrotron facilities, as it provides not only transmission imaging data, such as STXM, but also phase information simultaneously. The technique provides 
very high resolution over large sample areas and is characterized by the high reliance on computationally demanding techniques for the reconstruction of the results.

The single image (probe) is a diffraction image that, via numerical inversion, can provide us with the original transmission image in terms of intensity and phase. This is a complex mathematical problem with multiple solutions. To obtain the right solution, the sample is scanned at a step size smaller than the probe size, ensuring adequate overlapping of subsequent illuminated areas, acquiring a diffraction pattern for each step in the raster scan. Indeed, the redundant information due to the oversampling allows computer algorithms to reconstruct reliably both the sample transmission function and the illuminating probe, recovering the amplitude and phase of both these signals. As in classical SXTM, by reconstructing a stack of images acquired at photon energies across the absorption edge of a specific chemical element, ptychography allows for XANES-type studies, as demonstrated in [64,65], providing sub-micrometric resolution chemical speciation.

In addition to ptychography experiments, the beamline has successfully tested the keyhole-CDI technique [61], which, by being a single-shot technique, is, in general, preferable for in situ dynamic studies, such as monitoring the dynamics of electrodeposition $[64,65]$, but which can also be used for biological samples [66].

Figure 4 outlines the direct-detection transmission X-ray ptychography setup at TwinMic, where ZP optics illuminates an area over a sample placed at a certain distance from the focus, while the sample is raster-scanned with a step size smaller than the probe size. Currently, the same previously mentioned back-illuminated Princeton CCD camera used for TXM is also employed for ptychography.

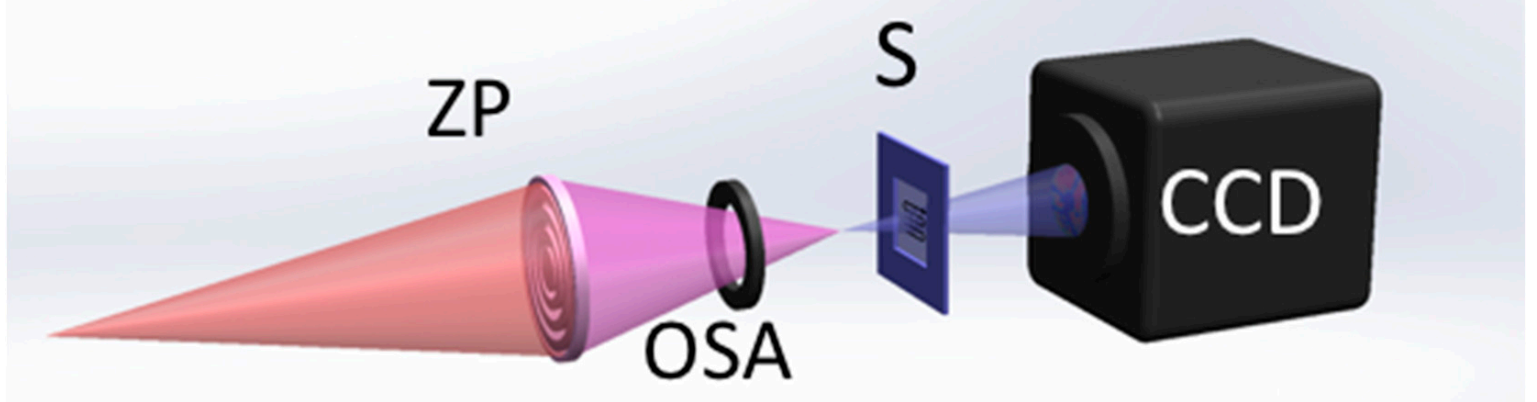

Figure 4. Schematic view of the TwinMic ptychography setup with the zone plate (ZP), the order-selecting aperture (OSA), the specimen (S), and the CCD camera.

Ptychography can be classified as a computational technique as it requires reconstruction similar to that of a computed tomography workflow. Advances in algorithms and computational resources have affected the quality and speed of reconstruction. TwinMic, in collaboration with the Elettra Scientific Computing group, has developed a specialized data acquisition and ptychographic reconstruction in-house software called SciComPty that allows for the state-of-the-art reconstruction and optimization of various experimental parameters. SciComPty [67] was developed and tested with data at energy ranges suitable for medical and biological studies. The system and the in-house computing expertise should allow noncomputational researchers to employ this technique for an easier absorption and phase imaging data analysis. 


\subsubsection{Compressive Sensing}

Originally introduced in the astronomy field, compressive sensing $[68,69]$ is an emerging method where image reconstruction is performed from a limited (ideally small) number of datasets without compromising the final quality. It is based on the assumption that the "most useful" datasets are smartly acquired, while the less significant ones can be easily extrapolated by a fast or small dataset. Inspired by this idea, we have recently developed in TwinMic a set of approaches [70,71] that allow us to perform dynamic scans where it is possible to skip points (sparse) and perform acquisitions with variable parameters (i.e., acquisition time). Such an approach leads to a substantial reduction in the required time, besides reducing the size of stored datasets. This reduction in terms of time, coupled with other technological and scientific advances such as new detectors or new sources, can produce maps of very large areas (one or two orders of magnitude higher than the standard ones), which could not be acquired with the traditional ways. Briefly, we proposed three different methods for optimizing the XRF data acquisition, where only the most significant XRF data are collected, by: (i) applying a mask based on a previously acquired absorption image (and therefore based on the sample morphology); (ii) applying an absorption threshold, and therefore acquiring the XRF signal only on specific regions, which represent the real sample (and not the support or the embedding medium); (iii) by applying a threshold on the XRF signal and therefore acquiring a longer XRF spectrum in the regions where a specific element of interest is present in higher concentrations. Naturally, such methods can also be applied as a combination, allowing an even smarter acquisition strategy.

Of course, these approaches can be extended to other kinds of microscopies or analytical techniques, as suggested or explored by other groups [72-75].

Compressive sensing is thus an imaging strategy that can represent a TwinMic imaging modality.

\subsection{Sample Preparation}

2.2.1. Balb /3T3 Mouse Fibroblast Cells Exposed to $\mathrm{CoFe}_{2} \mathrm{O}_{4}$ NanoParticles (NPs) and Met5A Cells Exposed to Crocidolite Fibres

The Balb/3T3 mouse fibroblasts and Met5A cells were seeded on $100 \mathrm{~nm}$ thick silicon nitride $\left(\mathrm{Si}_{3} \mathrm{~N}_{4}\right)$ membranes contained in a 6-well plate (Corning, Costar) at the density of $10^{5}$ cells/well and covered with $3 \mathrm{~mL}$ of standard culture medium. After $24 \mathrm{~h}$, the medium was replaced with a treatment medium containing $1000 \mu \mathrm{M}$ of $\mathrm{CoFe}_{2} \mathrm{O}_{4} \mathrm{NPs}$ in the case of fibroblasts [43] or containing $5 \mathrm{ug} / \mathrm{mL}$ of crocidolite [33,76] in the case of Met5A cells.

$\mathrm{CoFe}_{2} \mathrm{O}_{4} \mathrm{NPs}$ were supplied by Colorobbia S.p.A. (Vinci-Firenze, Italy) as a suspension in $100 \%$ diethylene glycol (DEG). The particles show a diameter of $36 \mathrm{~nm}$ in the stock suspension but clustering up to $600 \mathrm{~nm}$ in the culture cell medium [77]. Crocidolite Asbestos UICC Standard fibres (SPI\#02704-AB) were supplied by SPI Supplies Division, Structure Probe, Inc. (West Chester, PA 19381-0656, USA). Dried fibres were suspended in sterile phosphate-buffered saline (PBS) at a concentration of $10 \mathrm{mg} / \mathrm{mL}$. The fibres were sonicated for $1 \mathrm{~h}$ and dispersed by a 5-10 $\mathrm{mL}$ syringe with a 21-gauge needle [33].

After $24 \mathrm{~h}$, the treatment was removed and the samples were washed twice with PBS without calcium, magnesium, and sodium bicarbonate and fixed with $4 \%(v / v)$ of paraformaldehyde solution prepared in PBS buffer [43].

\subsubsection{Ovarian Tissue}

The ovarian tissue reported here belonged to a sample grouping already studied [36,78] and was obtained from a patient at the Gynaecological and Obstetrics Department of the Institute of Maternal and Child Health IRCCS Burlo Garofolo, Trieste, Italy. The research on this type of sample had been approved by the Institutional Review Board of IRCCS Burlo Garofolo (Trieste, Italy). The tissue sample was prepared as reported in [36,78], where it was fixed in $2.5 \%$ glutaraldehyde (Electron Microscopy Sciences, Hatfield, PA, USA) prepared in $0.1 \mathrm{M}$ of sodium cacodylate buffer ( $\mathrm{pH}$ 7.2-7.4), and a post-fixation 
treatment was performed with osmium tetroxide $1 \%$ in the same buffer. The sample was then dehydrated with increasing concentrations of ethanol (50\%, 70\%, 90\%, and 100\%) and embedded in epoxy resin (DurcupanTM Fluka) [36,78]. A $2 \mu \mathrm{m}$ thick section of this was placed on a $4 \mu \mathrm{m}$ thick Ultralene film for XRF analysis.

\subsubsection{Human Spermatozoa}

The sample reported here belonged to a sample collection already described [79] and was obtained from healthy volunteers. In particular, the specimens were the discarded residuals from fertilization procedures. After centrifugation $\left(10^{\prime}\right.$ at $\left.300 \times g\right)$, the spermatozoa were fixed in paraformaldehyde (4\% in phosphate-buffered solution) for $20 \mathrm{~min}$ at room temperature. After washing twice in physiologic solution $\left(\mathrm{NaCl} 0.9 \%, 15^{\prime}\right.$ at $\left.300 \times g\right)$, they were re-suspended in $15 \mu \mathrm{L}$ of physiological solution $(\sim 100.000$ cells). For XRF imaging, $2 \mu \mathrm{L}$ of samples was dropped on $\mathrm{Si}_{3} \mathrm{~N}_{4}$ windows, let to dry, washed in water, and dried again [32].

\subsubsection{Rhodnius Prolixus}

The insect was transversally cut at the junction between prothorax and mesothorax segments of the body and fixed with formalin. After that, the insects were embedded in paraffin and then cut in a microtome. A $5 \mu \mathrm{m}$ thick section was placed on a $4 \mu \mathrm{m}$ thick ultralene film. More details are given in [80].

\subsubsection{Coronary Artery Sample}

The coronary artery presented in this paper is part of the research project illustrated in [81]. The coronary artery of a wistar rat was removed, cleaned, and placed in 10\% neutralbuffered formalin solution. After that, the tissue was embedded in Paraplast Plus (SigmaAldrich, St. Louis, MO, USA) and fixed. The sample was sectioned with a microtome to a $5 \mu \mathrm{m}$-thick slice and deposited on a $4 \mu \mathrm{m}$-thick ultralene film. All procedures were carried out according to international guidelines of animal protection and were approved by the Ethics Committee on Animal Experimentation of the State University of Rio de Janeiro (Process CEA/018/2018).

\section{Results}

In this section, we present how the abovementioned TwinMic imaging techniques can be applied in the medical and biological fields, providing new insights in specific scientific questions.

\subsection{STXM Coupled with LEXRF}

\subsubsection{Nanotoxicology}

NPs, such as cobalt ferrites, are increasingly being used in the biomedical field, as drugdelivery agents, biosensors, or imaging contrast agents [82,83]. The study of the complex $\mathrm{NP}$-cell interaction is crucial to better understand their uptake mechanism and cytotoxicity effects.

To this aim, the capabilities offered by the TwinMic microscope are particularly suited to study the behavior of $\mathrm{CoFe}_{2} \mathrm{O}_{4}$ NPs at the single-cell level [43,77]. STXM sub-micron resolution, combined with LEXRF trace element sensitivity, can provide the simultaneous correlation between cellular changes in shape and morphology and the elemental distributions of both cells and NPs.

Figure 5 shows an example of LEXRF mapping performed on mouse fibroblast cells exposed to NPs. Cells are well visible by the distribution of $\mathrm{C}, \mathrm{O}, \mathrm{Na}$, and $\mathrm{Mg}$, with a higher level of $\mathrm{O}$ and $\mathrm{Na}$ in the areas corresponding to the cell nuclei. The co-localization of $\mathrm{Co}$ and Fe reveals the distribution of NPs, which appear to be preferentially located in the perinuclear/cytoplasmic region of the cells. Moreover, NPs often appear to coalesce between them, forming aggregates or vesicles. More details can be found in $[43,77,84]$. 

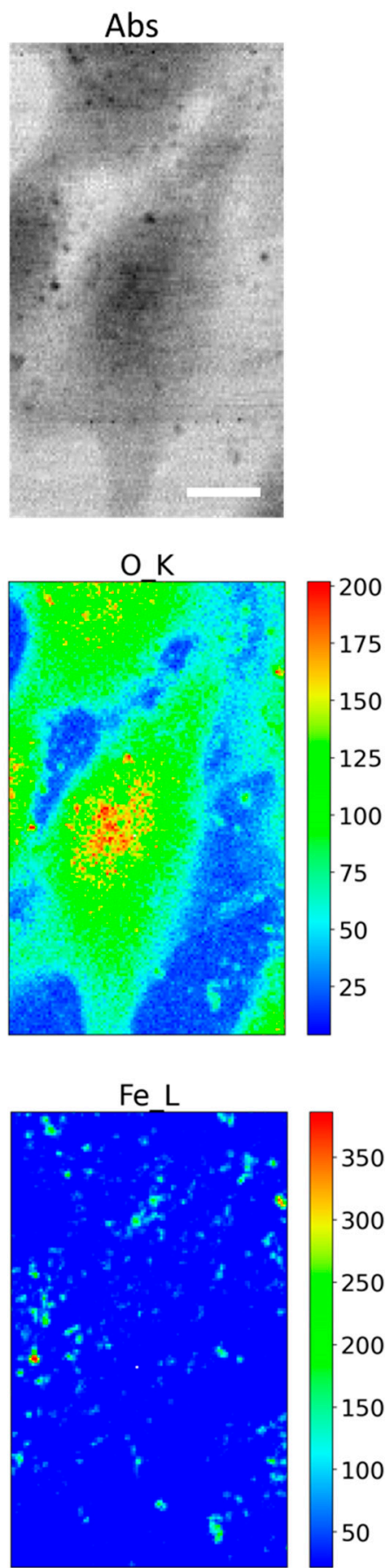

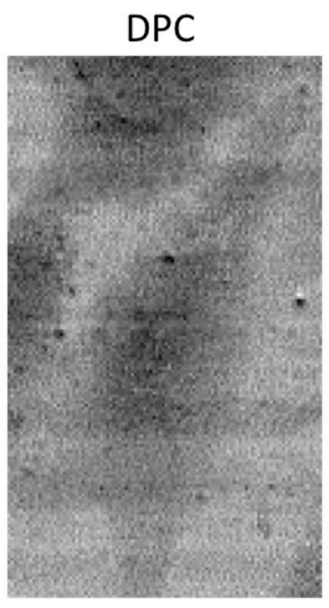

$\mathrm{Na} \mathrm{K}$
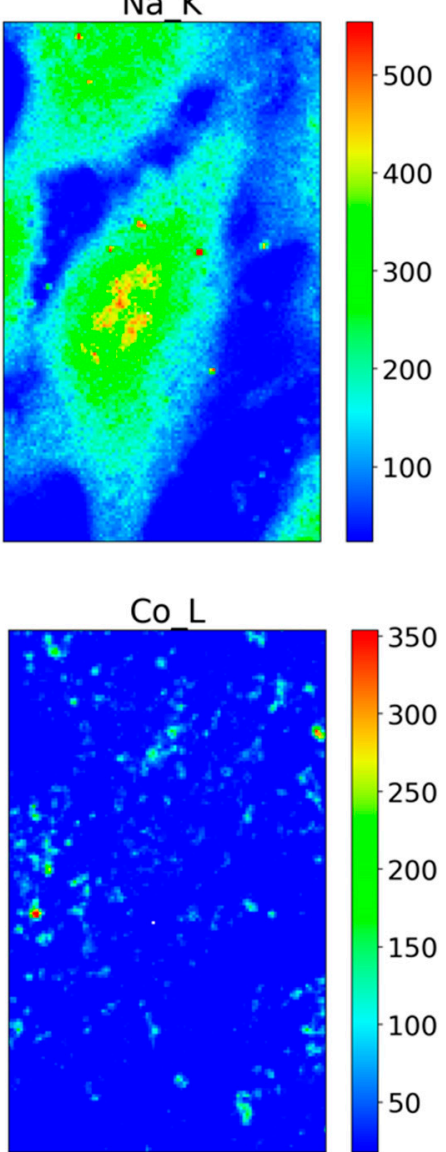
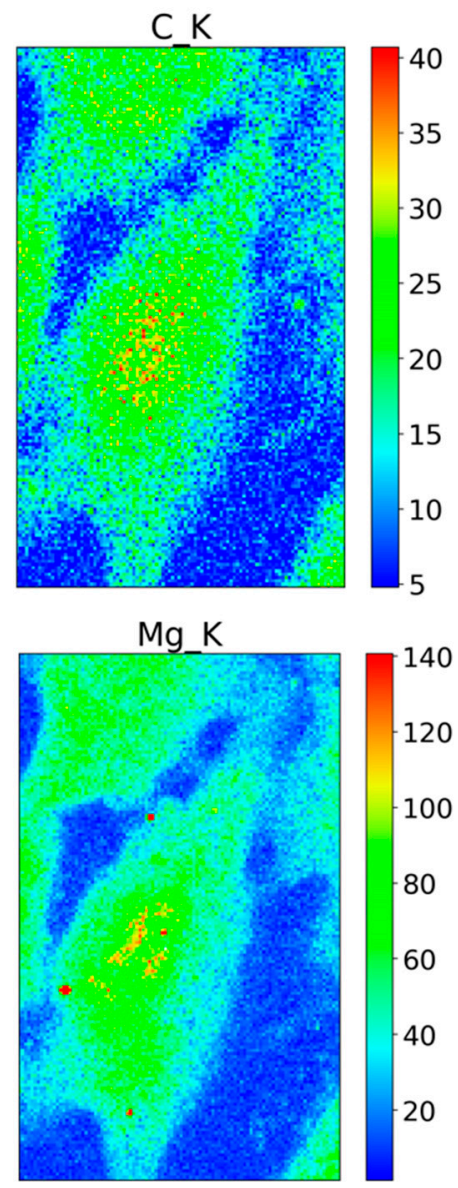

EO

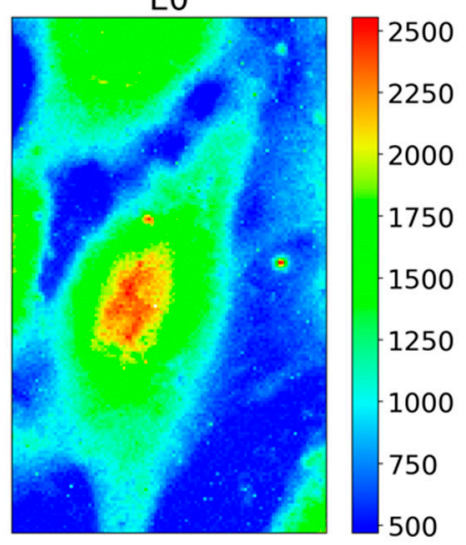

Figure 5. Absorption (Abs) and differential phase contrast (DPC) images of mouse fibroblast cells cultured on Si3N4 membranes and exposed to a $500 \mu \mathrm{M}$ concentration of $\mathrm{CoFe} 2 \mathrm{O} 4 \mathrm{NPs}$, depicted with the corresponding XRF maps of $\mathrm{C}$, $\mathrm{O}$, $\mathrm{Na}, \mathrm{Mg}, \mathrm{Fe}, \mathrm{Co}$, and Scattering (E0). The maps were collected at $1.5 \mathrm{keV}$ over an area of $40 \mu \mathrm{m} \times 70 \mu \mathrm{m}$ with a $400 \mathrm{~nm}$ step size, with a $4 \mathrm{~s} /$ pixel acquisition time for XRF. Scale bar is $10 \mu \mathrm{m}$.

\subsubsection{Reproductive Medicine}

The combination of STXM with LEXRF allows for an efficient localization of specific elements in biological specimens. In reproductive medicine, elements such as $\mathrm{Na}$ or $\mathrm{Mg}$ have been shown to be directly related to the functionality of the biological system. The TwinMic setup offers the capability to localize these elements in oocyte and spermatozoa (Figures 6 and 7). At the moment, we cannot provide a quantitative analysis of the elements present in the biological specimens, which requires suitable reference standards 
with similar composition, hard to find in the soft $\mathrm{X}$-ray regime. However, comparisons between samples can still be made by evaluating the relative variation of a specific element.

\section{Abs}
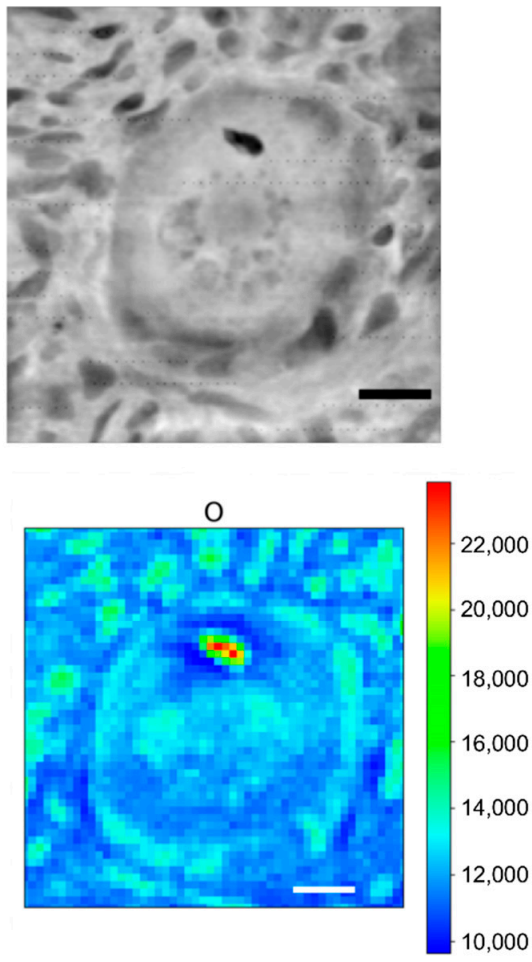

$\mathrm{X}$ mom
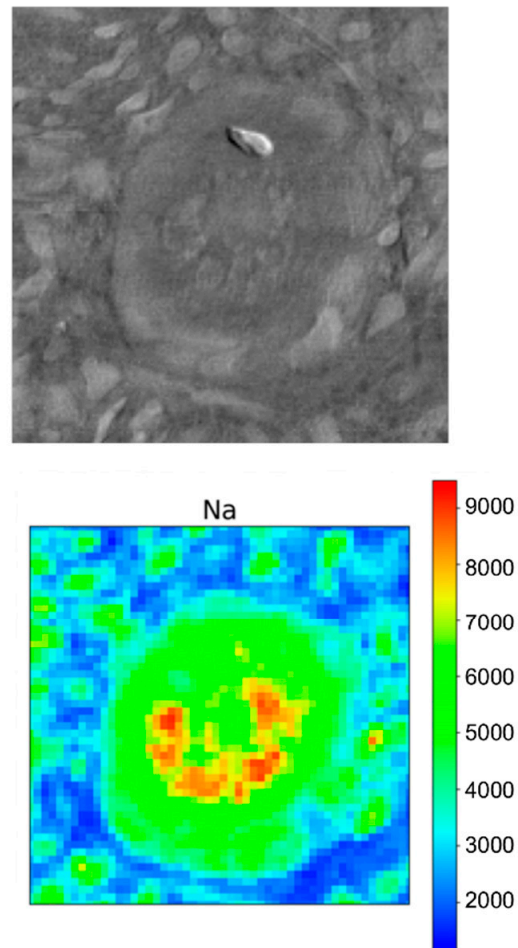

Y mom
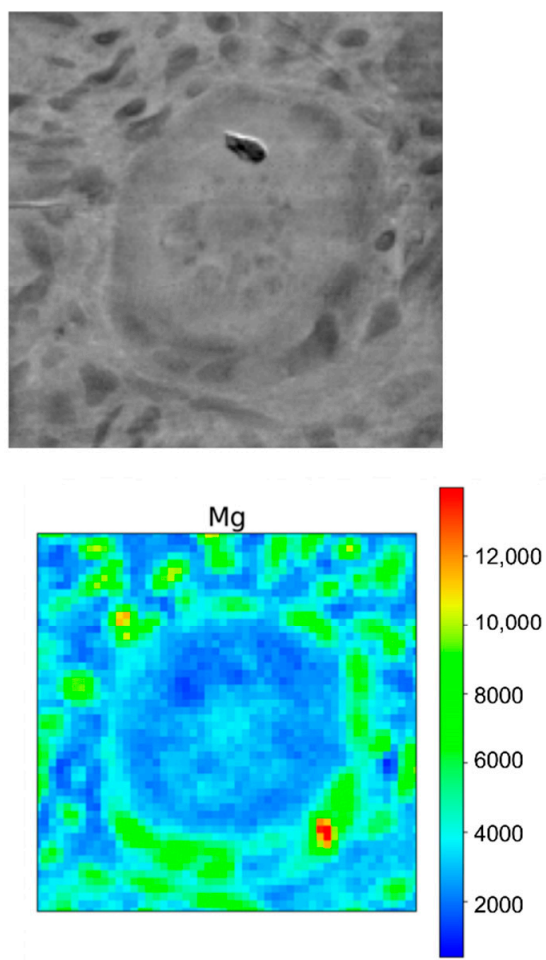

Figure 6. Absorption (Abs) and differential phase contrast in $X(X$ mom) and $Y(Y$ mom) images of primary oocyte in an ovarian tissue, depicted with the corresponding $\mathrm{XRF}$ maps of $\mathrm{O}, \mathrm{Na}$, and $\mathrm{Mg}$. The maps were collected at $1.5 \mathrm{keV}$ over an area of $70 \mu \mathrm{m} \times 70 \mu \mathrm{m}$ (STXM images) or $60 \mu \mathrm{m} \times 60 \mu \mathrm{m}$ (XRF maps) with $300 \mathrm{~nm}$ and $1 \mu \mathrm{m}$ step sizes, respectively, with a $7 \mathrm{~s} /$ pixel acquisition time for XRF. Scale bar is $10 \mu \mathrm{m}$.
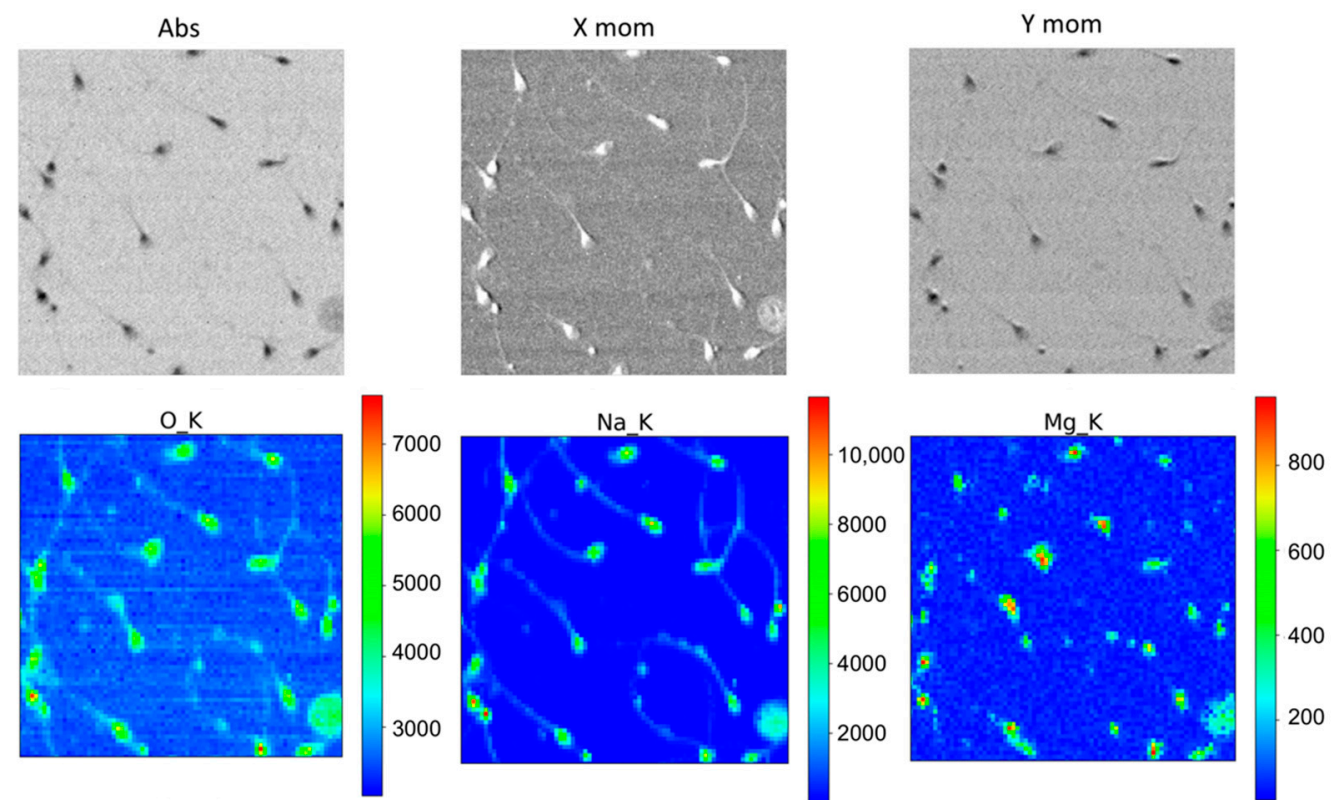

Figure 7. Absorption (Abs) and differential phase contrast in $X(X$ mom $)$ and $Y(Y$ mom) images of spermatozoa deposited on $\mathrm{Si}_{3} \mathrm{~N}_{4}$ windows, depicted with the corresponding XRF maps of $\mathrm{O}, \mathrm{Na}$, and $\mathrm{Mg}$. The maps were collected at $1.5 \mathrm{keV}$ over an area of $80 \mu \mathrm{m} \times 80 \mu \mathrm{m}$ with a $400 \mathrm{~nm}$ and $1 \mu \mathrm{m}$ step size for STXM images and XRF, respectively, and a $10 \mathrm{~s} /$ pixel acquisition time for XRF. Scale bar is $10 \mu \mathrm{m}$. 
In a previous study related to artificial reproductive techniques, we indeed demonstrated that STXM can be of help in analyzing the quality of follicles inside ovary tissue samples and the kind of damage resulting from a slow freezing protocol of cryopreservation, by monitoring the morphology of the cells and the distribution of several physiologically relevant elements such as $\mathrm{Na}, \mathrm{Mg}$, and $\mathrm{O}$ [36]. In particular, it was found that among other effects, low-quality follicles, frequent in the freeze-thawed tissues, show a high $\mathrm{Na}$ level in the ooplasm [78].

Figure 6 shows the absorption and differential phase contrast images of an oocyte in a human ovarian tissue slide together with the corresponding distribution of oxygen, sodium, and magnesium, which was collected in the frame of this research.

Analogously, STXM coupled with LEXRF has been successful in revealing elemental changes in spermatozoa treated with photobiomodulation therapy [85] and in capacitation procedures [32], where elements such as $\mathrm{Na}$ and $\mathrm{Mg}$ seem to play an important role. Additionally, elemental changes were revealed when sperm cells were exposed to oxidative stress conditions [79]. Figure 7 depicts an example of STXM and LEXRF mapping performed on healthy spermatozoa. The data confirm the capability of our technique in localizing specific elements inside sperm heads and tails.

\subsection{Ptychography}

Figure 8 of this section shows expected imaging results using far-field ptychography [86] at TwinMic for biological studies. In particular, it shows a reconstruction of diffraction data acquired at $1.02 \mathrm{keV}$, achieving a resolution better than $50 \mathrm{~nm}$ for a sample area larger than $60 \times 60 \mu^{2}$, where the specimen is a group of chemically fixed human mesothelial cells (Met5A) exposed to crocidolite fibres. The high quality of the obtained image allows us to better recognize the subcellular structures and to identify the nanofibres internalized by the cells. The spatial resolution achieved with this setup can be seen in Figure S1, showing the reconstruction of a tungsten Siemens Star test reference object with a $20 \mu \mathrm{m}$ external diameter. As can be seen from Figure S1, panel C, a spatial resolution better than $50 \mathrm{~nm}$ could be reached.

A

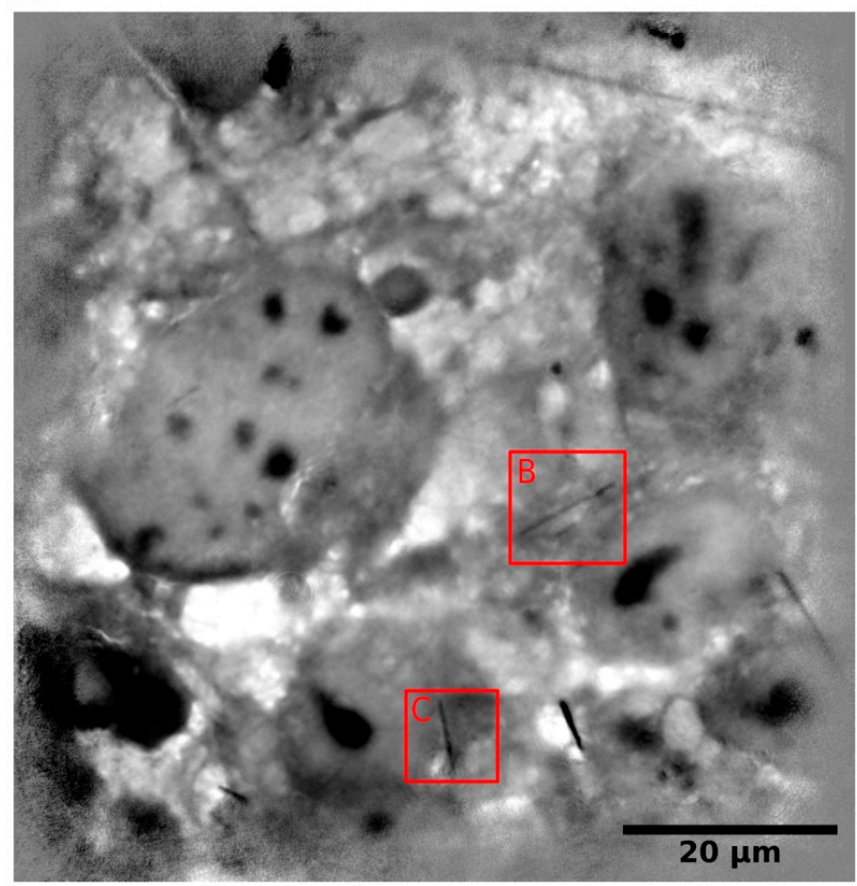

B

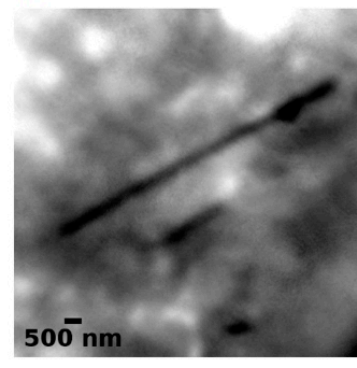

C

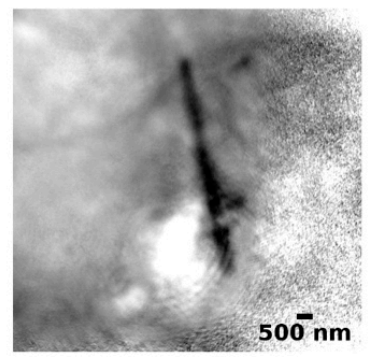

Figure 8. Panel (A) shows the ptychographic phase reconstruction of chemically fixed mesothelial cells. This is an example of a large field of view $\left(>60 \times 60 \mu \mathrm{m}^{2}\right)$ examined with a high resolution (approx. $50 \mathrm{~nm}$ ). Panel (B) and (C) show enlarged ROIs, as indicated in panel (A). 
The same type of scan could be subsequently performed across an energy range that covers a specific absorption edge, eventually allowing for XANES analysis.

As ptychography is more complex and less diffused than older standard techniques such as STXM and full-field, such images are unique and of particular interest for the research community.

\subsection{Compressive Sensing}

Even though compressive sensing XRF can be applied to any kind of sample, it appears to be particularly useful for biological/medical samples, where the specimens are often of irregular shapes or discontinuous by nature (such as cell or alveolar structures in lungs) and with chemical elements of interest located in specific limited areas. On the other hand, for such kind of samples, in order to collect statistically significant data, it may be necessary to scan large areas (millimeters wide) or several samples/patients.

In this section, we thus present two examples that allow us to appreciate the benefits of the compressive sensing approach in biology and medicine.

The first example applies to a specific field of growing interest in biomedical research due to recent and pressing concerns over viruses and pathogens, especially in relation to pandemics and the climate crisis $[87,88]$. In particular, the study of insects, and more widely, of other arthropods and invertebrates, can bring fundamental insights when dealing with pathogens causing diseases potentially harmful or fatal for humans [89]. Insects are indeed often vector/carriers for the transmission of known pathogens and might also foster the spread of novel virulence factors into existing ones [90,91]. Moreover, many invertebrates possess highly specific virus-host interactions and immune responses, as well as a variety of regulatory mechanisms either to eliminate toxic compounds from their cells, or to balance the uptake of specific elements and intracellular sequestration [92].

The TwinMic setup, combined with compressive sensing acquisition, allows for a more efficient STXM-LEXRF analysis for insect systems, providing both the scan of the entire specimen and the spatial distributions of elements with micrometric resolution.

The example in Figure 9 shows results of a study on Rhodnius prolixus that may be of significance for vector control studies, particularly toward the control of the Chagas Disease $[80,93]$. LEXRF maps allow the study of tissue/organ-specific accumulation patterns, as well as element distributions in various insect's life stages, which may have significant implications for toxicology and medicine. More generally, this kind of information can help in understanding insect-virus interactions and the modality of transmission with vertebrates.

This case exemplifies how compressive sensing can vastly improve time-effective acquisition, which is very advantageous for the scanning of large areas or a large sample set. Indeed, by acquiring the XRF signal only in the areas with an absorption signal below a specific threshold, only $21 \%$ of the total area was mapped without losing essential information, allowing one to save around $79 \%$ of the total time required with a standard LEXRF rectangular mapping. The absorption threshold was defined by acquiring a lowresolution STXM scan with step size of $5 \mu \mathrm{m}$. The overall complete STXM scan (Figure 9) coupled with selective LEXRF mapping (Figure 10) lasted $42 \mathrm{~h}$. 

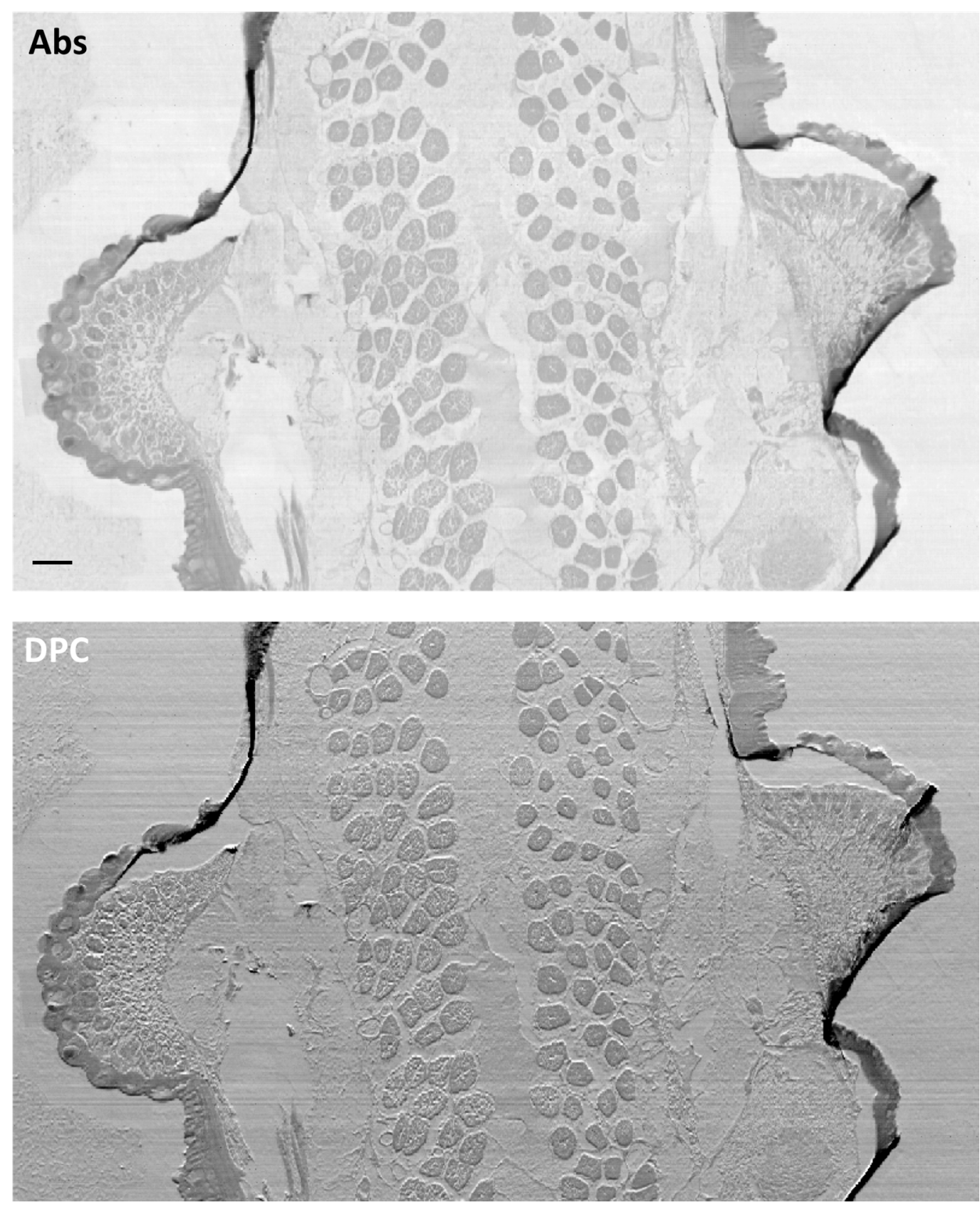

Figure 9. Absorption (Abs) and differential phase contrast (DPC) images of a section of a Rhodnius prolixus head [80] acquired at a $1.7 \mathrm{keV}$ excitation energy over an area of $1200 \mu \mathrm{m} \times 720 \mu \mathrm{m}$ with a $1.5 \mu \mathrm{m}$ step size and probe size, and $50 \mathrm{~ms}$ acquisition time. Scale bar is $50 \mu \mathrm{m}$.

The distributions of $\mathrm{C}, \mathrm{O}, \mathrm{Na}, \mathrm{Mg}, \mathrm{Al}$, and $\mathrm{Fe}$ are shown in Figure 10, which can be correlated to the insect morphological features shown in Figure 9 [80].

The second example of compressive sensing LEXRF concerns the research field of imaging combined with element localization in extended organs, such as arteries and aortic arch [81].

XRF has been shown to be a powerful tool to investigate aortic systems in connection to several medical treatments and diseases, e.g., atherosclerotic plaques $[94,95]$ radiotherapy and chemotherapy treatments [96] or calcification effects [37,97]. Moreover, the same technique can reveal interesting connections between the distribution of specific elements and physical and mechanical properties of aortic media, as presented in the work of Z. Qin and coauthors [98]. 
C K

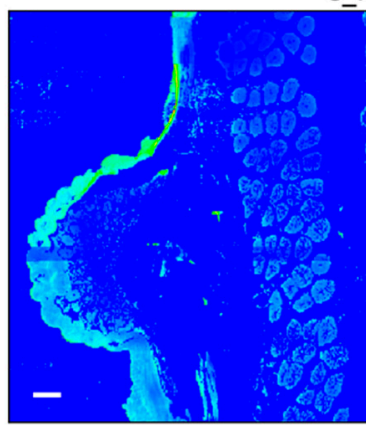

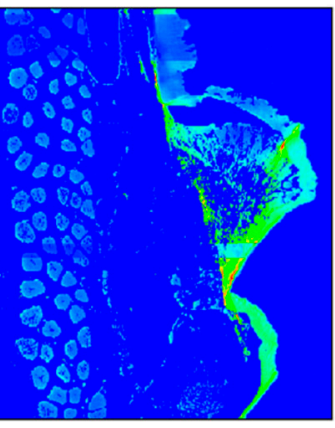

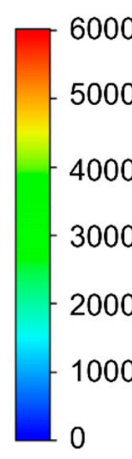

Na_K

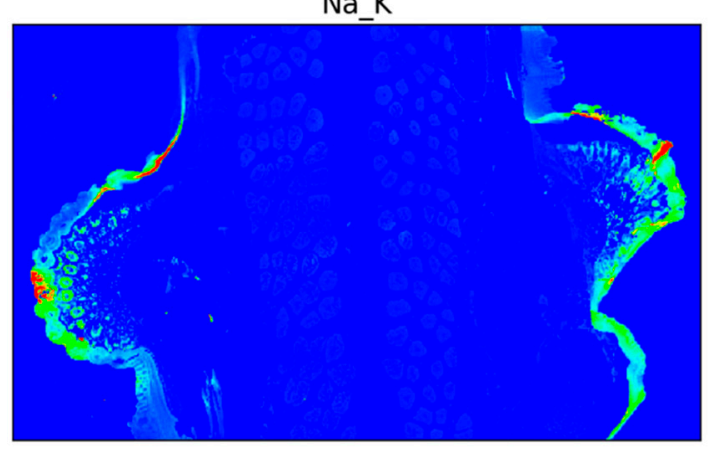

Al_K

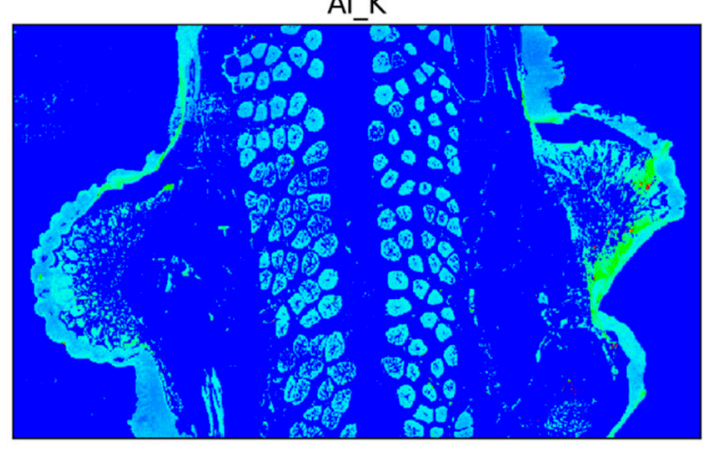

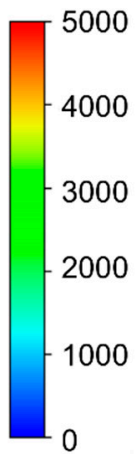

0

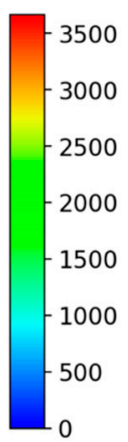

O_K

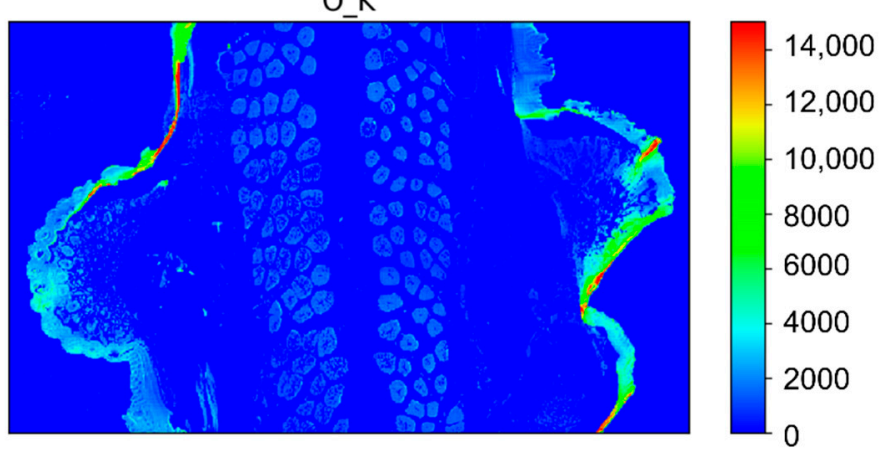

4,000

.

000

000

000

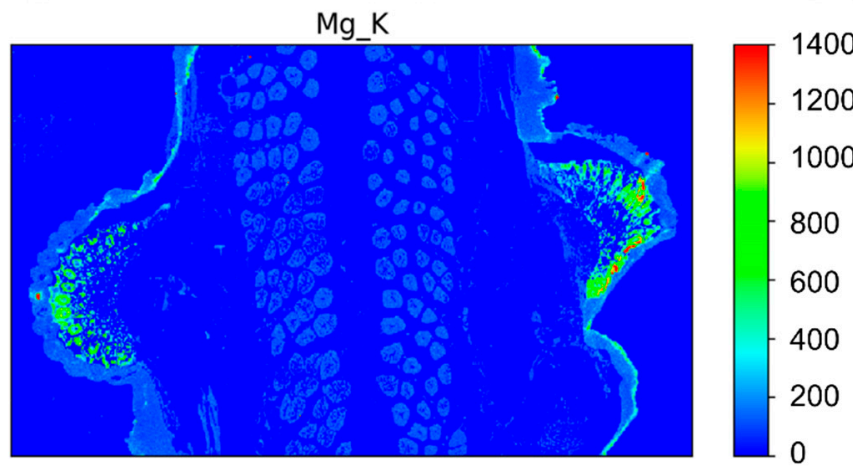

Fe L

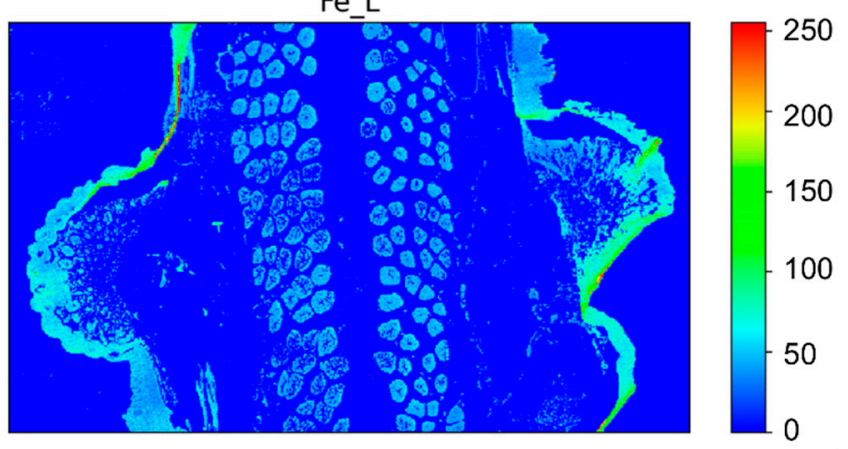

Figure 10. LEXRF maps of $\mathrm{C}, \mathrm{O}, \mathrm{Na}, \mathrm{Mg}, \mathrm{Al}$, and $\mathrm{Fe}$ acquired at a $1.7 \mathrm{keV}$ excitation energy with a $1.5 \mu \mathrm{m}$ step size and probe size, and $2 \mathrm{~s}$ acquisition time. The STXM images were acquired over an area of $1200 \mu \mathrm{m} \times 720 \mu \mathrm{m}$ with a $1.5 \mu \mathrm{m}$ step size and probe size, while the XRF signal was collected only on selected areas, based on a preselected absorption threshold value in the absorption signal. Scale bar is $50 \mu \mathrm{m}$.

The internal structure of the coronary artery wall is quite complex with different layers of tissue [81]. Collecting the LEXRF information from the entire section instead of a small area may bring several advantages to the medical investigation. However, one of the main issues in fluorescence mapping of such a large area is related to the long acquisition time. The compressive sensing method can thus play a key role in overcoming this limitation. Figure 11 shows the absorption and differential phase contrast images of a whole section of an aortic arch of a hypertensive rat [81], while Figure 12 depicts the corresponding LEXRF signal of $\mathrm{C}, \mathrm{Mg}$, and $\mathrm{Na}$ elements. The bottom row of Figure 12 also shows a sub-region of whole mapped area, to better highlight the coronary artery structure and elemental distribution. Again, by acquiring the XRF signal only in the areas with an absorption signal below a specific threshold, only $25 \%$ of the total area was mapped without losing essential information and saving around $75 \%$ of the total time required with a standard LEXRF rectangular mapping. 

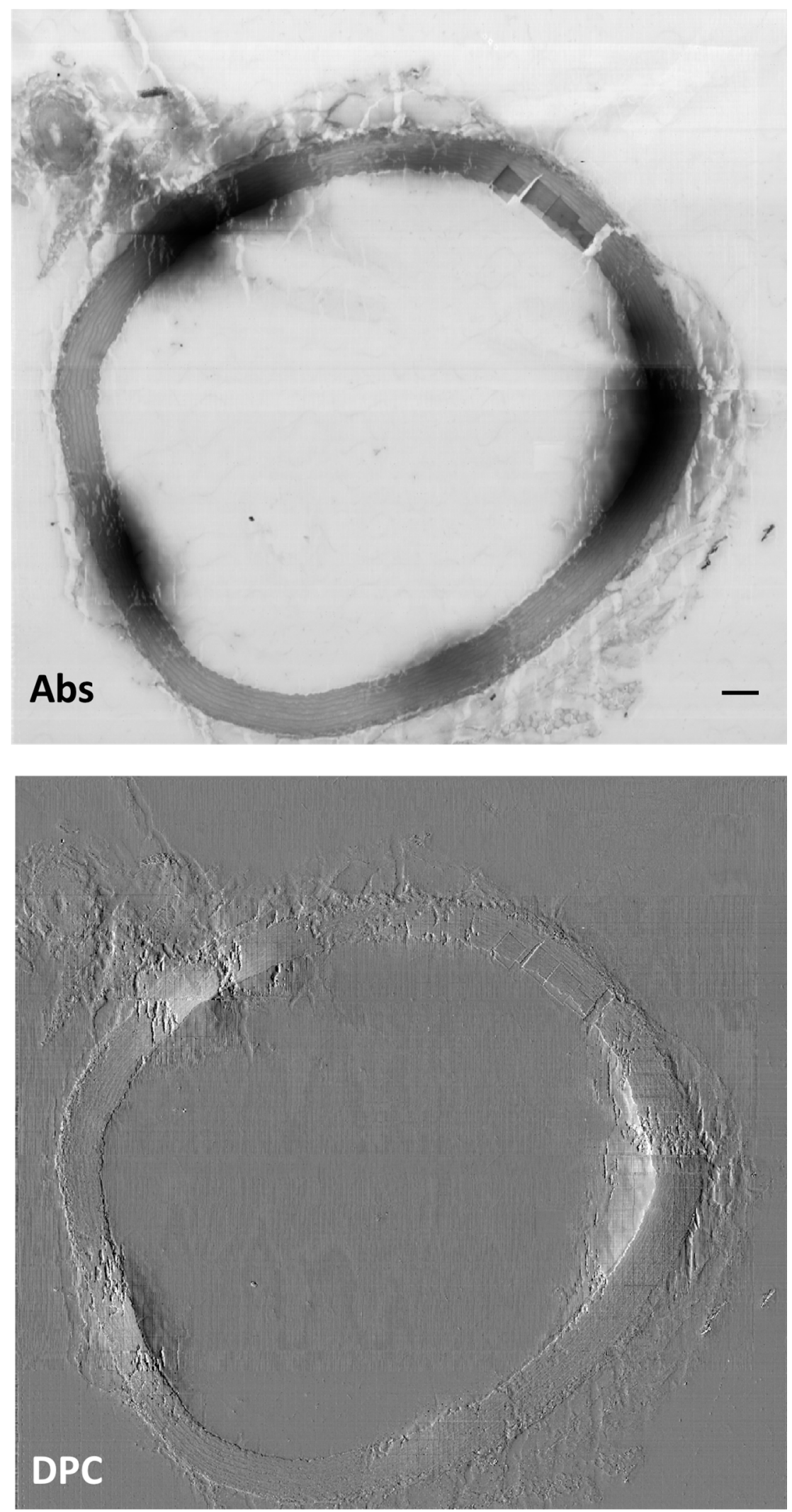

Figure 11. Absorption (Abs) and differential contrast image (DPC) of a section of coronary artery from a rat [81], acquired at a $1.5 \mathrm{keV}$ excitation energy with a $2.5 \mu \mathrm{m}$ step size, over an area of $2100 \mu \mathrm{m} \times 2000 \mu \mathrm{m}$. Scale bar is $100 \mu \mathrm{m}$. 

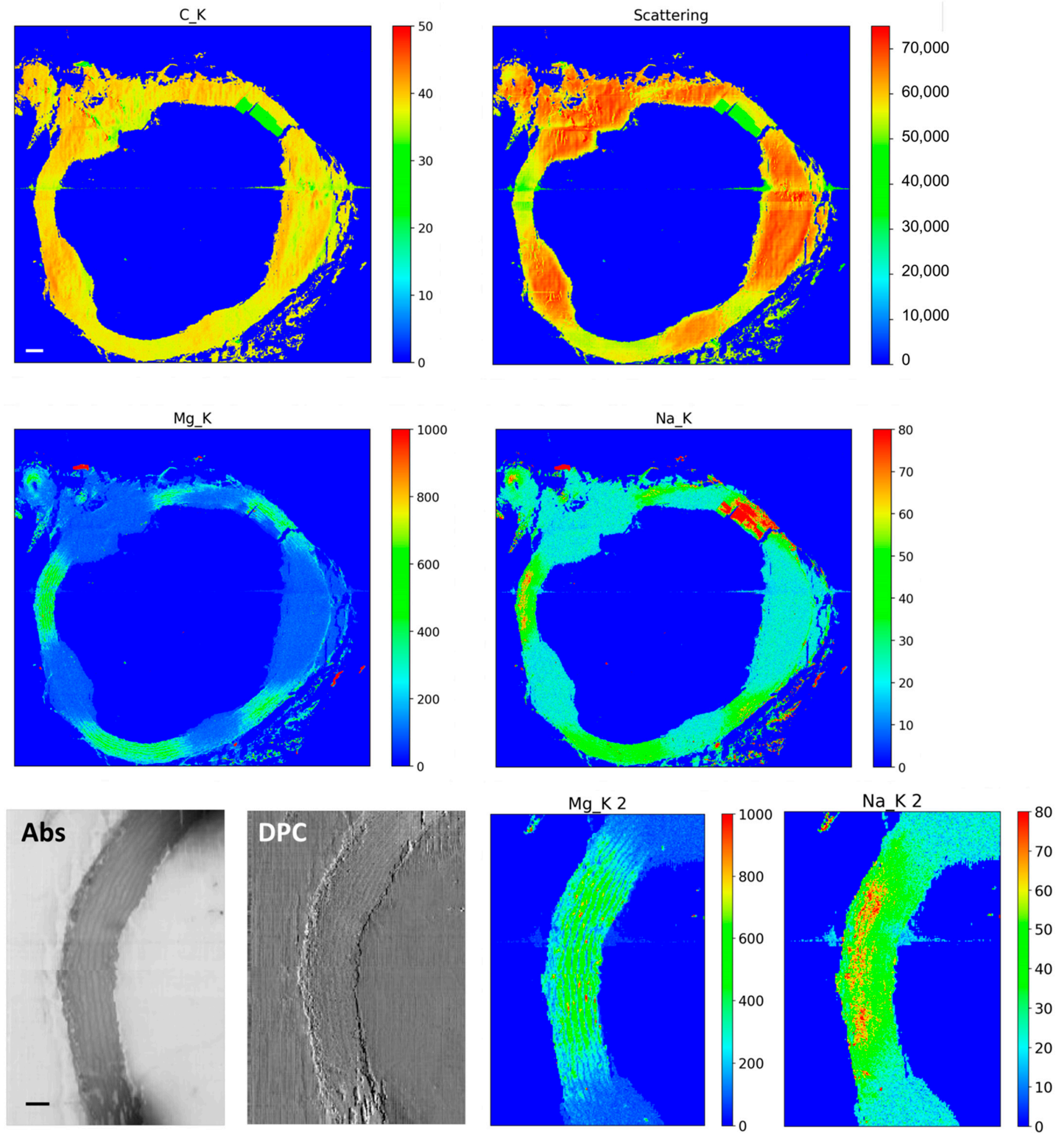

Figure 12. XRF maps of $\mathrm{C}, \mathrm{Na}, \mathrm{Mg}$, and scattering signal, collected on the coronary artery section shown in Figure 11 , at $1.7 \mathrm{keV}$, with a step size of $2.5 \mu \mathrm{m}$ and a $1 \mathrm{~s}$ acquisition time per pixel, only on the areas with an absorption signal below a specific pre-selected threshold. The bottom row depicts a sub-region of the absorption (Abs) and differential phase contrast (DPC) images shown in Figure 11 together with the corresponding LXERF maps of Mg and $\mathrm{Na}$ (Panels Mg_K 2 and Na_K 2, respectively). Scale bar in map C is $100 \mu \mathrm{m}$, while in panel Abs, it is $50 \mu \mathrm{m}$. 


\section{Discussion and Conclusions}

In the present paper, the TwinMic imaging and spectroscopic potentialities in biology and biomedicine were highlighted by showing relevant examples in the life sciences field. The possibility of deploying different imaging modalities coupled with X-ray fluorescence spectroscopy makes TwinMic a very attractive tool for the life sciences community.

Although TwinMic has been successfully employed to provide answers or information for different research topics, there is a continuous trend to improve its capabilities in terms of: (i) sensitivity, by means of new XRF detector systems and new imaging detectors, such as CMOS ones; (ii) spatial resolution, by means of more reliable sample stages, higherresolution optics systems, and last but not least, by improving the ptychography imaging mode; (iii) chemical element accessibility, by extending its energy range until $4.2 \mathrm{keV}$, as foreseen in the next years to come.

TwinMic upgrades will also be pushed forward by new possible requirements or wishes from the life sciences community.

Another successful key point of TwinMic, which has not been stressed in the current paper, is that its setup modularity and flexibility (i.e., motors stages and sample holders) allow it to be easily complemented with other synchrotron techniques, such as FTIR spectromicroscopy [42], XRF at higher energies [37,38], and microtomography [34], often by analyzing the very same specimens.

Supplementary Materials: The following are available online at https: / www.mdpi.com/article/10 $.3390 /$ app11167216/s1, Figure S1: (A) Ptychographic reconstruction of a $20 \mu \mathrm{m}$ diameter tungsten Siemens Star test pattern. (B) Zoom of the area indicated with the red box in Panel A. (C) Profile graph extracted along the red line indicated in Panel B, showing an achievable spatial resolution better than $50 \mathrm{~nm}$.

Author Contributions: Conceptualization, A.G. and G.K.; methodology, A.G., F.B. and G.K.; software, R.B., F.B. and G.K.; formal analysis, V.B., G.G., F.G., F.B. and G.K.; investigation, A.G. and L.P.; resources, A.G. and L.P.; data curation, F.B. and G.K.; writing-original draft preparation, A.G.; writing-review and editing, A.G., V.B., G.G., L.P., F.B. and G.K.; visualization, A.G., V.B., G.G. and F.G. All authors have read and agreed to the published version of the manuscript.

Funding: This research received no external funding. This research acknowledges the support of the internal Elettra Sincrotrone Trieste project Advanced Integrated Imaging Initiative.

Institutional Review Board Statement: For the human ovarian tissue and human sperm samples, the ethical committees' statements are the ones already produced for the already published works $[36,78,85]$. No new samples were analyzed in this study. For the coronary artery, all procedures were carried out according to international guidelines of animal protection and were approved by the Ethics Committee on Animal Experimentation of the State University of Rio de Janeiro (Process CEA/018/2018), as done for [81], as no new samples were analyzed.

Informed Consent Statement: Informed consent was obtained from all subjects involved in the studies.

Data Availability Statement: The data presented in this study are available on request from the corresponding author. The data are not publicly available due to privacy reasons including an embargo period according to the facility's scientific data policy.

Acknowledgments: The authors are grateful to Giacomo Ceccone from JRC (Ispra, Italy) for providing the fibroblast cells exposed to $\mathrm{CoFe}_{2} \mathrm{O}_{4}$ NPs; to Gabriela Sena Souza, Arissa Oliveira Pickler, and Regina Cely Barroso from the University of Rio de Janeiro (Brazil) for the insect and coronary artery samples.

Conflicts of Interest: The authors declare no conflict of interest.

\section{References}

1. Kaulich, B.; Thibault, P.; Gianoncelli, A.; Kiskinova, M. Transmission and Emission X-ray Microscopy: Operation Modes, Contrast Mechanisms and Applications. J. Phys. Condens. Matter 2011, 23, 083002. [CrossRef]

2. Soft X-ray Microscopy with Diffractive Optics. In Soft X-ray and Extreme Ultraviolet Radiation: Principles and Applications; Attwood, D. (Ed.) Cambridge University Press: Cambridge, UK, 1999; pp. 337-394; ISBN 978-1-139-16442-9. 
3. Kilcoyne, A.L.D.; Tyliszczak, T.; Steele, W.F.; Fakra, S.; Hitchcock, P.; Franck, K.; Anderson, E.; Harteneck, B.; Rightor, E.G.; Mitchell, G.E.; et al. Interferometer-Controlled Scanning Transmission X-ray Microscopes at the Advanced Light Source. J. Synchrotron Radiat. 2003, 10, 125-136. [CrossRef]

4. Kaznatcheev, K.V.; Karunakaran, C.H.; Lanke, U.D.; Urquhart, S.G.; Obst, M.; Hitchcock, A.P. Soft X-ray Spectromicroscopy Beamline at the CLS: Commissioning Results. Nucl. Instrum. Methods Phys. Res. Sect. A Accel. Spectrometers Detect. Assoc. Equip. 2007, 582, 96-99. [CrossRef]

5. SoftiMAX-MAX IV. Available online: https://www.maxiv.lu.se/accelerators-beamlines/beamlines/softimax/ (accessed on 7 April 2021).

6. Welcome to I08-The Diamond Scanning X-ray Microscopy Beamline-Diamond Light Source. Available online: https://www. diamond.ac.uk/Instruments/Imaging-and-Microscopy/I08.html (accessed on 7 April 2021).

7. Gianoncelli, A.; Kourousias, G.; Merolle, L.; Altissimo, M.; Bianco, A. Current Status of the TwinMic Beamline at Elettra: A Soft X-ray Transmission and Emission Microscopy Station. J. Synchrotron Radiat. 2016, 23, 1526-1537. [CrossRef]

8. Shin, H.J.; Kim, N.; Kim, H.S.; Lee, W.W.; Lee, C.S.; Kim, B. A Scanning Transmission X-ray Microscope at the Pohang Light Source. J Synchrotron Radiat. 2018, 25, 878-884. [CrossRef]

9. Takeichi, Y.; Inami, N.; Suga, H.; Miyamoto, C.; Ueno, T.; Mase, K.; Takahashi, Y.; Ono, K. Design and Performance of a Compact Scanning Transmission X-ray Microscope at the Photon Factory. Rev. Sci. Instrum. 2016, 87, 013704. [CrossRef]

10. Raabe, J.; Tzvetkov, G.; Flechsig, U.; Böge, M.; Jaggi, A.; Sarafimov, B.; Vernooij, M.G.C.; Huthwelker, T.; Ade, H.; Kilcoyne, D.; et al. PolLux: A New Facility for Soft X-ray Spectromicroscopy at the Swiss Light Source. Rev. Sci. Instrum. 2008, 79, 113704. [CrossRef] [PubMed]

11. Sorrentino, A.; Nicolás, J.; Valcárcel, R.; Chichón, F.J.; Rosanes, M.; Avila, J.; Tkachuk, A.; Irwin, J.; Ferrer, S.; Pereiro, E. MISTRAL: A Transmission Soft X-ray Microscopy Beamline for Cryo Nano-Tomography of Biological Samples and Magnetic Domains Imaging. J. Synchrotron Rad. 2015, 22, 1112-1117. [CrossRef] [PubMed]

12. Guttmann, P.; Werner, S.; Rehbein, S.; Habel, C.; Schneider, G. First Results from the X-ray Microscopy Beamline U41-PGM1-XM at BESSY II. Microsc. Microanal. 2018, 24, 202-203. [CrossRef]

13. Le Gros, M.A.; McDermott, G.; Cinquin, B.P.; Smith, E.A.; Do, M.; Chao, W.L.; Naulleau, P.P.; Larabell, C.A. Biological Soft X-ray Tomography on Beamline 2.1 at the Advanced Light Source. J. Synchrotron Radiat. 2014, 21, 1370-1377. [CrossRef]

14. Kaulich, B.; Bacescu, D.; Susini, J.; David, C.; Di Fabrizio, E.; Morrison, G.R.; Charalambous, P.; Thieme, J.; Wilhein, T.; Kovac, J.; et al. A European Twin X-ray Microscopy Station Commissioned at ELETTRA. Conf. Proc. Ser. IPAP 2006, 7, $22-25$.

15. Gianoncelli, A.; Kaulich, B.; Alberti, R.; Klatka, T.; Longoni, A.; De Marco, A.; Marcello, A.; Kiskinova, M. Simultaneous Soft X-ray Transmission and Emission Microscopy. Nucl. Instrum. Methods Phys. Res. Sect. A Accel. Spectrometers Detect. Assoc. Equip. 2009, 608, 195-198. [CrossRef]

16. Gianoncelli, A.; Kourousias, G.; Stolfa, A.; Kaulich, B. Recent Developments at the TwinMic Beamline at ELETTRA: An 8 SDD Detector Setup for Low Energy X-ray Fluorescence. J. Phys. Conf. Ser. 2013, 425, 182001. [CrossRef]

17. Gianoncelli, A.; Kourousias, G.; Altissimo, M.; Bedolla, D.E.; Merolle, L.; Stolfa, A.; Shin, H.-J. Combining Multiple Imaging Techniques at the TwinMic X-ray Microscopy Beamline. Aip. Conf. Proc. 2016, 1764, 030002. [CrossRef]

18. Vásquez, G.C.; Peche-Herrero, M.A.; Maestre, D.; Gianoncelli, A.; Ramírez-Castellanos, J.; Cremades, A.; González-Calbet, J.M.; Piqueras, J. Laser-Induced Anatase-to-Rutile Transition in $\mathrm{TiO}_{2}$ Nanoparticles: Promotion and Inhibition Effects by Fe and $\mathrm{Al}$ Doping and Achievement of Micropatterning. J. Phys. Chem. C 2015, 119, 11965-11974. [CrossRef]

19. Bozzini, B.; Gianoncelli, A.; Kaulich, B.; Kiskinova, M.; Prasciolu, M.; Sgura, I. Metallic Plate Corrosion and Uptake of Corrosion Products by Nafion in Polymer Electrolyte Membrane Fuel Cells. ChemSusChem 2010, 3, 846-850. [CrossRef]

20. Bozzini, B.; Gianoncelli, A.; Bocchetta, P.; Dal Zilio, S.; Kourousias, G. Fabrication of a Sealed Electrochemical Microcell for in Situ Soft X-ray Microspectroscopy and Testing with In Situ Co-Polypyrrole Composite Electrodeposition for Pt-Free Oxygen Electrocatalysis. Anal. Chem. 2014, 86, 664-670. [CrossRef] [PubMed]

21. Bozzini, B.; Bocchetta, P.; Gianoncelli, A.; Kourousias, G.; Kiskinova, M.; Zilio, S.D. In Situ Soft X-ray Fluorescence and Absorption Microspectroscopy: A Study of Mn-Co/Polypyrrole Electrodeposition. J. Vac. Sci. Technol. A 2015, 33, 031102. [CrossRef]

22. Bozzini, B.; Gianoncelli, A.; Kourousias, G.; Boniardi, M.; Casaroli, A.; Dal Zilio, S.; Hussain, R.; Abyaneh, M.K.; Kiskinova, M.; Mele, C.; et al. The Role of Chromium in the Corrosion Performance of Cobalt- and Cobalt-Nickel Based Hardmetal Binders: A Study Centred on X-ray Absorption Microspectroscopy. Int. J. Refract. Met. Hard Mater. 2020, 92, 105320. [CrossRef]

23. Kopittke, P.M.; Moore, K.L.; Lombi, E.; Gianoncelli, A.; Ferguson, B.J.; Blamey, P.; Menzies, N.; Nicholson, T.; McKenna, B.; Wang, P.; et al. Identification of the Primary Lesion of Toxic Aluminum (Al) in Plant Roots. Plant Physiol. 2015, 167, $1402-1411$. [CrossRef] [PubMed]

24. Kopittke, P.M.; Gianoncelli, A.; Kourousias, G.; Green, K.; McKenna, B.A. Alleviation of Al Toxicity by Si Is Associated with the Formation of Al-Si Complexes in Root Tissues of Sorghum. Front. Plant Sci. 2017, 8, 2189. [CrossRef]

25. Regvar, M.; Eichert, D.; Kaulich, B.; Gianoncelli, A.; Pongrac, P.; Vogel-Mikus, K.; Kreft, I. New Insights into Globoids of Protein Storage Vacuoles in Wheat Aleurone Using Synchrotron Soft X-ray Microscopy. J. Exp. Bot. 2011, 62, 3929-3939. [CrossRef] [PubMed]

26. Tolrà, R.; Vogel-Mikuš, K.; Hajiboland, R.; Kump, P.; Pongrac, P.; Kaulich, B.; Gianoncelli, A.; Babin, V.; Barceló, J.; Regvar, M.; et al. Localization of Aluminium in Tea (Camellia Sinensis) Leaves Using Low Energy X-ray Fluorescence Spectro-Microscopy. J. Plant Res. 2011, 124, 165-172. [CrossRef] [PubMed] 
27. Werner, F.; Mueller, C.W.; Thieme, J.; Gianoncelli, A.; Rivard, C.; Höschen, C.; Prietzel, J. Micro-Scale Heterogeneity of Soil Phosphorus Depends on Soil Substrate and Depth. Sci. Rep. 2017, 7, 3203. [CrossRef]

28. Klančnik, K.; Vogel-Mikuš, K.; Kelemen, M.; Vavpetič, P.; Pelicon, P.; Kump, P.; Jezeršek, D.; Gianoncelli, A.; Gaberščik, A. Leaf Optical Properties Are Affected by the Location and Type of Deposited Biominerals. J. Photochem. Photobiol. B Biol. 2014, 140, 276-285. [CrossRef]

29. Medas, D.; De Giudici, G.; Pusceddu, C.; Casu, M.A.; Birarda, G.; Vaccari, L.; Gianoncelli, A.; Meneghini, C. Impact of Zn Excess on Biomineralization Processes in Juncus Acutus Grown in Mine Polluted Sites. J. Hazard. Mater. 2019, 370, 98-107. [CrossRef] [PubMed]

30. Medas, D.; De Giudici, G.; Casu, M.A.; Musu, E.; Gianoncelli, A.; Iadecola, A.; Meneghini, C.; Tamburini, E.; Sprocati, A.R.; Turnau, K.; et al. Microscopic Processes Ruling the Bioavailability of Zn to Roots of Euphorbia Pithyusa L. Pioneer Plant. Environ. Sci. Technol. 2015, 49, 1400-1408. [CrossRef] [PubMed]

31. Giudici, G.D.; Medas, D.; Meneghini, C.; Casu, M.A.; Gianoncelli, A.; Iadecola, A.; Podda, S.; Lattanzi, P. Microscopic Biomineralization Processes and Zn Bioavailability: A Synchrotron-Based Investigation of Pistacia Lentiscus L. Roots. Environ. Sci. Pollut. Res. 2015, 22, 19352-19361. [CrossRef] [PubMed]

32. Pascolo, L.; Zupin, L.; Gianoncelli, A.; Giolo, E.; Luppi, S.; Martinelli, M.; De Rocco, D.; Sala, S.; Crovella, S.; Ricci, G. XRF Analyses Reveal That Capacitation Procedures Produce Changes in Magnesium and Copper Levels in Human Sperm. Nucl. Instrum. Methods Phys. Res. Sect. B Beam Interact. Mater. At. 2019, 459, 120-124. [CrossRef]

33. Cammisuli, F.; Giordani, S.; Gianoncelli, A.; Rizzardi, C.; Radillo, L.; Zweyer, M.; Da Ros, T.; Salomé, M.; Melato, M.; Pascolo, L. Iron-Related Toxicity of Single-Walled Carbon Nanotubes and Crocidolite Fibres in Human Mesothelial Cells Investigated by Synchrotron XRF Microscopy. Sci. Rep. 2018, 8, 706. [CrossRef]

34. Pascolo, L.; Sena, G.; Gianoncelli, A.; Cernogoraz, A.; Kourousias, G.; Metscher, B.D.; Romano, F.; Zito, G.; Pacilè, S.; Barroso, R.; et al. Hard and Soft X-ray Imaging to Resolve Human Ovarian Cortical Structures. J. Synchrotron Radiat. 2019, 26, 1322-1329. [CrossRef] [PubMed]

35. Gianoncelli, A.; Rizzardi, C.; Salomon, D.; Canzonieri, V.; Pascolo, L. Nano-Imaging of Environmental Dust in Human Lung Tissue by Soft and Hard X-ray Fluorescence Microscopy. Spectrochim. Acta Part B At. Spectrosc. 2018, 147, 71-78. [CrossRef]

36. Pascolo, L.; Venturin, I.; Gianoncelli, A.; Salomé, M.; Altissimo, M.; Bedolla, D.E.; Giolo, E.; Martinelli, M.; Luppi, S.; Romano, F.; et al. Morphological and Chemical Information in Fresh and Vitrified Ovarian Tissues Revealed by X-ray Microscopy and Fluorescence: Observational Study. J. Inst. 2018, 13, C06003. [CrossRef]

37. Pascolo, L.; Gianoncelli, A.; Rizzardi, C.; Tisato, V.; Salomé, M.; Calligaro, C.; Salvi, F.; Paterson, D.; Zamboni, P. Calcium Micro-Depositions in Jugular Truncular Venous Malformations Revealed by Synchrotron-Based XRF Imaging. Sci. Rep. 2014, 4, 6540. [CrossRef] [PubMed]

38. Pascolo, L.; Gianoncelli, A.; Rizzardi, C.; de Jonge, M.; Howard, D.; Paterson, D.; Cammisuli, F.; Salomé, M.; Paoli, P.D.; Melato, M.; et al. Focused X-ray Histological Analyses to Reveal Asbestos Fibers and Bodies in Lungs and Pleura of Asbestos-Exposed Subjects. Microsc. Microanal. 2016, 22, 1062-1071. [CrossRef] [PubMed]

39. Pascolo, L.; Zabucchi, G.; Gianoncelli, A.; Kourousias, G.; Trevisan, E.; Pascotto, E.; Casarsa, C.; Ryan, C.; Lucattelli, M.; Lungarella, G.; et al. Synchrotron X-ray Microscopy Reveals Early Calcium and Iron Interaction with Crocidolite Fibers in the Lung of Exposed Mice. Toxicol. Lett. 2016, 241, 111-120. [CrossRef]

40. Poitry-Yamate, C.; Gianoncelli, A.; Kaulich, B.; Kourousias, G.; Magill, A.W.; Lepore, M.; Gajdosik, V.; Gruetter, R. Feasibility of Direct Mapping of Cerebral Fluorodeoxy-D-Glucose Metabolism in Situ at Subcellular Resolution Using Soft X-ray Fluorescence. J. Neurosci. Res. 2013, 91, 1050-1058. [CrossRef] [PubMed]

41. Poitry-Yamate, C.; Gianoncelli, A.; Kourousias, G.; Kaulich, B.; Lepore, M.; Gruetter, R.; Kiskinova, M. Direct Mapping of 19F in 19FDG-6P in Brain Tissue at Subcellular Resolution Using Soft X-ray Fluorescence. In Journal of Physics: Conference Series; IOP Publishing: Bristol, UK, 2013; Volume 463.

42. Mitri, E.; Millucci, L.; Merolle, L.; Bernardini, G.; Vaccari, L.; Gianoncelli, A.; Santucci, A. A New Light on Alkaptonuria: A Fourier-Transform Infrared Microscopy (FTIRM) and Low Energy X-ray Fluorescence (LEXRF) Microscopy Correlative Study on a Rare Disease. Biochim. Biophys. Acta 2017, 1861, 1000-1008. [CrossRef]

43. Marmorato, P.; Ceccone, G.; Gianoncelli, A.; Pascolo, L.; Ponti, J.; Rossi, F.; Salomé, M.; Kaulich, B.; Kiskinova, M. Cellular Distribution and Degradation of Cobalt Ferrite Nanoparticles in Balb/3T3 Mouse Fibroblasts. Toxicol. Lett. 2011, 207, 128-136. [CrossRef]

44. Luchinat, E.; Gianoncelli, A.; Mello, T.; Galli, A.; Banci, L. Combining In-Cell NMR and X-ray Fluorescence Microscopy to Reveal the Intracellular Maturation States of Human Superoxide Dismutase 1. Chem. Commun. 2014, 51, 584-587. [CrossRef]

45. Picone, G.; Cappadone, C.; Pasini, A.; Lovecchio, J.; Cortesi, M.; Farruggia, G.; Lombardo, M.; Gianoncelli, A.; Mancini, L.; Ralf H., M.; et al. Analysis of Intracellular Magnesium and Mineral Depositions during Osteogenic Commitment of 3D Cultured Saos2 Cells. Int. J. Mol. Sci. 2020, 21, 2368. [CrossRef]

46. Kraljević Pavelić, S.; Micek, V.; Bobinac, D.; Bazdulj, E.; Gianoncelli, A.; Krpan, D.; Žuvić, M.; Eisenwagen, S.; Stambrook, P.J.; Pavelić, K. Treatment of Osteoporosis with a Modified Zeolite Shows Beneficial Effects in an Osteoporotic Rat Model and a Human Clinical Trial. Exp. Biol. Med. 2021, 246, 529-537. [CrossRef] [PubMed] 
47. Raneri, S.; Giannoncelli, A.; Mascha, E.; Toniolo, L.; Roveri, M.; Lazzeri, A.; Coltelli, M.B.; Panariello, L.; Lezzerini, M.; Weber, J. Inspecting Adhesion and Cohesion of Protectives and Consolidants in Sandstones of Architectural Heritage by X-ray Microscopy Methods. Mater. Charact. 2019, 156, 109853. [CrossRef]

48. Morrison, G.R.; Niemann, B. Differential Phase Contrast X-ray Microscopy. In X-ray Microscopy and Spectromicroscopy; Thieme, D.J., Schmahl, P.D.G., Rudolph, D.D., Umbach, P.D.E., Eds.; Springer: Berlin/Heidelberg, Germany, 1998; pp. 85-94; ISBN 978-3-64272108-3.

49. Morrison, G.R.; Gianoncelli, A.; Kaulich, B.; Bacescu, D.; Kovac, J. A Fast-Readout CCD System for Configured-Detector Imaging in STXM. In Proceedings of the 8th International Conference X-ray Microscopy IPAP Conference Series, Himeji, Japan, 26-30 July 2005; pp. 377-379.

50. Gianoncelli, A.; Morrison, G.R.; Kaulich, B.; Bacescu, D.; Kovac, J. Scanning Transmission X-ray Microscopy with a Configurable Detector. Appl. Phys. Lett. 2006, 89, 251117. [CrossRef]

51. Feser, M.; Hornberger, B.; Jacobsen, C.; De Geronimo, G.; Rehak, P.; Holl, P.; Strüder, L. Integrating Silicon Detector with Segmentation for Scanning Transmission X-ray Microscopy. Nucl. Instrum. Methods Phys. Res. Sect. A Accel. Spectrometers Detect. Assoc. Equip. 2006, 565, 841-854. [CrossRef]

52. Amati, M.; Gregoratti, L.; Zeller, P.; Greiner, M.; Scardamaglia, M.; Junker, B.; Ruß, T.; Weimar, U.; Barsan, N.; Favaro, M.; et al. Near Ambient Pressure Photoelectron Spectro-Microscopy: From Gas-Solid Interface to Operando Devices. J. Phys. D Appl. Phys. 2021, 54, 204004. [CrossRef]

53. Bombelli, L.; Manotti, M.; Altissimo, M.; Kourousias, G.; Alberti, R.; Gianoncelli, A. Towards On-the-Fly X-ray Fluorescence Mapping in the Soft X-ray Regime. X-ray Spectrom. 2019, 48, 325-329. [CrossRef]

54. Gianoncelli, A.; Bufon, J.; Ahangarianabhari, M.; Altissimo, M.; Bellutti, P.; Bertuccio, G.; Borghes, R.; Carrato, S.; Cautero, G.; Fabiani, S.; et al. A New Detector System for Low Energy X-ray Fluorescence Coupled with Soft X-ray Microscopy: First Tests and Characterization. Nucl. Instrum. Methods Phys. Res. Sect. A Accel. Spectrometers Detect. Assoc. Equip. 2016, 816, 113-118. [CrossRef]

55. Bufon, J.; Schillani, S.; Altissimo, M.; Bellutti, P.; Bertuccio, G.; Billè, F.; Borghes, R.; Borghi, G.; Cautero, G.; Cirrincione, D.; et al. A New Large Solid Angle Multi-Element Silicon Drift Detector System for Low Energy X-ray Fluorescence Spectroscopy. J. Instrum. 2018, 13, C03032. [CrossRef]

56. Bufon, J.; Gianoncelli, A.; Ahangarianabhari, M.; Altissimo, M.; Bellutti, P.; Bertuccio, G.; Borghes, R.; Carrato, S.; Cautero, G.; Cicuttin, A.; et al. Towards a Multi-Element Silicon Drift Detector System for Fluorescence Spectroscopy in the Soft X-ray Regime. X-ray Spectrom. 2017, 46, 313-318. [CrossRef]

57. Bozzini, B.; Kourousias, G.; Bedolla, D.E.; Gianoncelli, A. Chemical-State Evolution of Ni in Mn-Ni/Polypyrrole Nanocomposites under Bifunctional Air Electrode Conditions, Investigated by Quasi-in Situ Multi-Scale Soft X-ray Absorption Spectroscopy. Mater. Today Energy 2017, 6, 154-163. [CrossRef]

58. Rodenburg, J.M. Ptychography and Related Diffractive Imaging Methods. Adv. Imaging Electron. Phys. 2008, 150, 87-184.

59. Thibault, P.; Dierolf, M.; Menzel, A.; Bunk, O.; David, C.; Pfeiffer, F. High-Resolution Scanning X-ray Diffraction Microscopy. Science 2008, 321, 379-382. [CrossRef] [PubMed]

60. Nugent, K.A. Coherent Methods in the X-ray Sciences. Adv. Phys. 2010, 59, 1-99. [CrossRef]

61. Abbey, B.; Nugent, K.A.; Williams, G.J.; Clark, J.N.; Peele, A.G.; Pfeifer, M.A.; de Jonge, M.; McNulty, I. Keyhole Coherent Diffractive Imaging. Nat. Phys. 2008, 4, 394-398. [CrossRef]

62. Williams, G.J.; Quiney, H.M.; Dhal, B.B.; Tran, C.Q.; Nugent, K.A.; Peele, A.G.; Paterson, D.; de Jonge, M.D. Fresnel Coherent Diffractive Imaging. Phys. Rev. Lett. 2006, 97, 025506. [CrossRef]

63. Abbey, B. From Grain Boundaries to Single Defects: A Review of Coherent Methods for Materials Imaging in the X-ray Sciences. JOM 2013, 65, 1183-1201. [CrossRef]

64. Kourousias, G.; Bozzini, B.; Gianoncelli, A.; Jones, M.W.M.; Junker, M.; van Riessen, G.; Kiskinova, M. Shedding Light on Electrodeposition Dynamics Tracked in Situ via Soft X-ray Coherent Diffraction Imaging. Nano Res. 2016, 9, 2046-2056. [CrossRef]

65. Kourousias, G.; Bozzini, B.; Jones, M.W.M.; Van Riessen, G.A.; Dal Zilio, S.; Billè, F.; Kiskinova, M.; Gianoncelli, A. Monitoring Dynamic Electrochemical Processes with In Situ Ptychography. Appl. Nanosci. 2018, 8, 627-636. [CrossRef]

66. Anthony, N.; Anthony, N.; Darmanin, C.; Bleackley, M.R.; Parisi, K.; Cadenazzi, G.; Holmes, S.; Anderson, M.A.; Nugent, K.A.; Nugent, K.A.; et al. Ptychographic Imaging of NaD1 Induced Yeast Cell Death. Biomed. Opt. ExpressBoe 2019, 10, 4964-4974. [CrossRef] [PubMed]

67. Guzzi, F.; Kourousias, G.; Billè, F.; Pugliese, R.; Gianoncelli, A.; Carrato, S. A Parameter Refinement Method for Ptychography Based on Deep Learning Concepts. arXiv 2021, arXiv:2105.08058.

68. Orović, I.; Papić, V.; Ioana, C.; Li, X.; Stanković, S. Compressive Sensing in Signal Processing: Algorithms and Transform Domain Formulations. Available online: https:/ /www.hindawi.com/journals/mpe/2016/7616393/ (accessed on 13 February 2020).

69. Amin, M.G.; Ahmad, F. Chapter 17-Through-the-Wall Radar Imaging: Theory and Applications. In Academic Press Library in Signal Processing; Sidiropoulos, N.D., Gini, F., Chellappa, R., Theodoridis, S., Eds.; Elsevier: Amsterdam, The Netherlands, 2014; Volume 2, pp. 857-909.

70. Kourousias, G.; Billè, F.; Borghes, R.; Alborini, A.; Sala, S.; Alberti, R.; Gianoncelli, A. Compressive Sensing for Dynamic XRF Scanning. Sci. Rep. 2020, 10, 9990. [CrossRef] [PubMed] 
71. Kourousias, G.; Billè, F.; Borghes, R.; Pascolo, L.; Gianoncelli, A. Megapixel Scanning Transmission Soft X-ray Microscopy Imaging Coupled with Compressive Sensing X-ray Fluorescence for Fast Investigation of Large Biological Tissues. Anal. Press 2021. [CrossRef]

72. Gamez, G. Compressed Sensing in Spectroscopy for Chemical Analysis. J. Anal. Spectrom. 2016, 31, 2165-2174. [CrossRef]

73. Pavillon, N.; Smith, N.I. Compressed Sensing Laser Scanning Microscopy. Opt. ExpressOe 2016, 24, 30038-30052. [CrossRef]

74. Kuo, H.-W.; Dorfi, A.E.; Esposito, D.V.; Wright, J.N. Compressed Sensing Microscopy with Scanning Line Probes. arXiv 2019, arXiv:1909.12342.

75. Ye, J.C. Compressed Sensing MRI: A Review from Signal Processing Perspective. BMC Biomed. Eng. 2019, 1, 8. [CrossRef] [PubMed]

76. Gianoncelli, A.; Delfino, R.; Sala, S.; Kourousias, G.; Giordani, S.; Romano, F.; Ricci, G.; Pascolo, L. Synchrotron Soft X-ray Microscopy and XRF to Image Single-Walled Carbon Nanotubes in Epithelial Cells. Nucl. Instrum. Methods Phys. Res. Sect. B Beam Interact. Mater. At. 2020, 465, 79-84. [CrossRef]

77. Gianoncelli, A.; Marmorato, P.; Ponti, J.; Pascolo, L.; Kaulich, B.; Uboldi, C.; Rossi, F.; Makovec, D.; Kiskinova, M.; Ceccone, G. Interaction of Magnetic Nanoparticles with U87MG Cells Studied by Synchrotron Radiation X-ray Fluorescence Techniques. $X$-ray Spectrom. 2013, 42, 316-320. [CrossRef]

78. Pascolo, L.; Venturin, I.; Gianoncelli, A.; Bortul, R.; Zito, G.; Giolo, E.; Salomé, M.; Bedolla, D.E.; Altissimo, M.; Zweyer, M.; et al. Light Element Distribution in Fresh and Frozen-Thawed Human Ovarian Tissues: A Preliminary Study. Reprod. Biomed. Online 2018, 37, 153-162. [CrossRef]

79. Pascolo, L.; Bedolla, D.E.; Vaccari, L.; Venturin, I.; Cammisuli, F.; Gianoncelli, A.; Mitri, E.; Giolo, E.; Luppi, S.; Martinelli, M.; et al. Pitfalls and Promises in FTIR Spectromicroscopy Analyses to Monitor Iron-Mediated DNA Damage in Sperm. Reprod. Toxicol. 2016, 61, 39-46. [CrossRef] [PubMed]

80. Sena, G.; Barroso, R.C.; Braz, D.; Nogueira, L.P.; Colaço, M.V.; Kourousias, G.; Altissimo, M.; Bedolla, D.E.; Tromba, G.; Azambuja, P.; et al. Evaluation of the Effects of Azadirachtin on Internal Structures of Rhodnius Prolixus Head Using LowEnergy X-ray Microfluorescence. Spectrochim. Acta Part B At. Spectrosc. 2021, 177, 106064. [CrossRef]

81. Pickler, A.; Mantuano, A.; Mota, C.L.; Ferreira-Machado, S.; Lau, C.C.; de Almeida, C.E.; Salata, C.; Nascimento, A.; Tanure, T.; Serqueira, L.; et al. Elemental Distribution in the Aortic Arch Using LEXRF: Side Effects of Angiotensin Receptor Blockers as Antihypertensive Treatment. Microchem. J. 2019, 148, 467-474. [CrossRef]

82. Baldi, G.; Bonacchi, D.; Innocenti, C.; Lorenzi, G.; Sangregorio, C. Cobalt Ferrite Nanoparticles: The Control of the Particle Size and Surface State and Their Effects on Magnetic Properties. J. Magn. Magn. Mater. 2007, 311, 10-16. [CrossRef]

83. Reddy, L.H.; Arias, J.L.; Nicolas, J.; Couvreur, P. Magnetic Nanoparticles: Design and Characterization, Toxicity and Biocompatibility, Pharmaceutical and Biomedical Applications. Chem. Rev. 2012, 112, 5818-5878. [CrossRef] [PubMed]

84. Kourousias, G.; Pascolo, L.; Marmorato, P.; Ponti, J.; Ceccone, G.; Kiskinova, M.; Gianoncelli, A. High-Resolution Scanning Transmission Soft X-ray Microscopy for Rapid Probing of Nanoparticle Distribution and Sufferance Features in Exposed Cells. X-ray Spectrom. 2015, 44, 163-168. [CrossRef]

85. Zupin, L.; Pascolo, L.; Gianoncelli, A.; Gariani, G.; Luppi, S.; Giolo, E.; Ottaviani, G.; Crovella, S.; Ricci, G. Synchrotron Radiation Soft X-ray Microscopy and Low Energy X-ray Fluorescence to Reveal Elemental Changes in Spermatozoa Treated with Photobiomodulation Therapy. Anal. Methods 2020, 12, 3691-3696. [CrossRef]

86. Wang, S.; Shapiro, D.; Kaznatcheev, K. X-ray Ptychography with Highly-Curved Wavefront. J. Phys. Conf. Ser. 2013, 463, 012040. [CrossRef]

87. Butler, C.D. Infectious Disease Emergence and Global Change: Thinking Systemically in a Shrinking World. Infect. Dis. Poverty 2012, 1, 5. [CrossRef]

88. Brooks, D.R.; Hoberg, E.P.; Boeger, W.A.; Trivellone, V. Emerging Infectious Disease: An Underappreciated Area of Strategic Concern for Food Security. Transbound Emerg. Dis. 2021. [CrossRef]

89. Waterfield, N.R.; Wren, B.W.; Ffrench-Constant, R.H. Invertebrates as a Source of Emerging Human Pathogens. Nat. Rev. Microbiol. 2004, 2, 833-841. [CrossRef] [PubMed]

90. Klempner, M.S.; Unnasch, T.R.; Hu, L.T. Taking a Bite out of Vector-Transmitted Infectious Diseases. N. Engl. J. Med. 2007, 356, 2567-2569. [CrossRef] [PubMed]

91. Baud, D.; Gubler, D.J.; Schaub, B.; Lanteri, M.C.; Musso, D. An Update on Zika Virus Infection. Lancet 2017, 390, 2099-2109. [CrossRef]

92. Palmer, W.H.; Varghese, F.S.; van Rij, R.P. Natural Variation in Resistance to Virus Infection in Dipteran Insects. Viruses 2018, 10, 118. [CrossRef]

93. Monteiro, F.A.; Barrett, T.V.; Fitzpatrick, S.; Cordon-Rosales, C.; Feliciangeli, D.; Beard, C.B. Molecular Phylogeography of the Amazonian Chagas Disease Vectors Rhodnius Prolixus and R. Robustus. Mol. Ecol. 2003, 12, 997-1006. [CrossRef]

94. Jung, C.; Kaul, M.G.; Bruns, O.T.; Dučić, T.; Freund, B.; Heine, M.; Reimer, R.; Meents, A.; Salmen, S.C.; Weller, H.; et al. Intraperitoneal Injection Improves the Uptake of Nanoparticle-Labeled High-Density Lipoprotein to Atherosclerotic Plaques Compared with Intravenous Injection. Circ. Cardiovasc. Imaging 2014, 7, 303-311. [CrossRef]

95. Gajda, M.; Banaś, K.; Banaś, A.; Jawień, J.; Mateuszuk, Ł.; Chłopicki, S.; Kwiatek, W.M.; Cichocki, T.; Falkenberg, G. Distribution of Selected Elements in Atherosclerotic Plaques of ApoE/LDLR-Double Knockout Mice Assessed by Synchrotron Radiation-Induced Micro-XRF Spectrometry. X-ray Spectrom. 2008, 37, 495-502. [CrossRef] 
96. Mantuano, A.; Mota, C.L.; Pickler, A.; Sena, G.; Braz, D.; Salata, C.; Almeida, C.E.D.; Costa, F.N.; Barroso, R.C. Elemental Distribution in Ascending Aortic after Radiotherapy and Chemotherapy by Low Energy X-ray Fluorescence Spectroscopy. J. Inst. 2018, 13, C05011. [CrossRef]

97. Lis, G.J.; Czapla-Masztafiak, J.; Kwiatek, W.M.; Gajda, M.; Jasek, E.; Jasinska, M.; Czubek, U.; Borchert, M.; Appel, K.; Nessler, J.; et al. Distribution of Selected Elements in Calcific Human Aortic Valves Studied by Microscopy Combined with SR-MXRF: Influence of Lipids on Progression of Calcification. Micron 2014, 67, 141-148. [CrossRef]

98. Qin, Z.; Toursarkissian, B.; Lai, B. Synchrotron Radiation X-ray Fluorescence Microscopy Reveals a Spatial Association of Copper on Elastic Laminae in Rat Aortic Media. Metallomics 2011, 3, 823-828. [CrossRef] [PubMed] 